\title{
State-of-art review of traffic signal control methods: challenges and opportunities
}

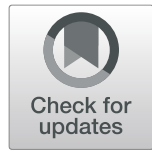

Syed Shah Sultan Mohiuddin Qadri ${ }^{*}$ D, Mahmut Ali Gökçe and Erdinç Öner

\begin{abstract}
Introduction: Due to the menacing increase in the number of vehicles on a daily basis, abating road congestion is becoming a key challenge these years. To cope-up with the prevailing traffic scenarios and to meet the everincreasing demand for traffic, the urban transportation system needs effective solution methodologies. Changes made in the urban infrastructure will take years, sometimes may not even be feasible. For this reason, traffic signal timing (TST) optimization is one of the fastest and most economical ways to curtail congestion at the intersections and improve traffic flow in the urban network.

Purpose: Researchers have been working on using a variety of approaches along with the exploitation of technology to improve TST. This article is intended to analyze the recent literature published between January 2015 and January 2020 for the computational intelligence $(\mathrm{Cl})$ based simulation approaches and $\mathrm{Cl}$-based approaches for optimizing TST and Traffic Signal Control (TSC) systems, provide insights, research gaps and possible directions for future work for researchers interested in the field.

Methods: In analyzing the complex dynamic behavior of traffic streams, simulation tools have a prominent place. Nowadays, microsimulation tools are frequently used in TST related researches. For this reason, a critical review of some of the widely used microsimulation packages is provided in this paper.

Conclusion: Our review also shows that approximately $77 \%$ of the papers included, utilizes a microsimulation tool in some form. Therefore, it seems useful to include a review, categorization, and comparison of the most commonly used microsimulation tools for future work. We conclude by providing insights into the future of research in these areas.

Keywords: Traffic signal timing optimization, Traffic signal control, Urban traffic, Microsimulation, Computational intelligence
\end{abstract}

\section{Introduction}

One of the biggest challenges for urban management is managing and mitigating traffic congestion. The number of vehicles in the urban network increasing day to day basis, which results in deterioration of traffic conditions. Due to this increase, blockage and long queues of vehicles form at intersections, leading commuters to lose valuable time, especially during rush hours. Apart from this, congestion of traffic also

\footnotetext{
* Correspondence: syedshahsultan@gmail.com

\section{Springer Open}

Department of Industrial Engineering, Yaşar University, Izmir, Turkey has detrimental effects on the health, environment, and the state's economy.

As to health, traffic congestion causes excessive fatigue, mental illnesses, and problems related to cardiovascular systems, such as the respiratory system and nervous system, resulting in a lower standard of life. Different pollutants are added to the environment through the heavy use of automobiles, which are one of the main reasons for different health-related issues and ecological damages [1, 2]. Environmentally, congestion of traffic leads to increased noise and air pollution $[3,4]$. (c) The Author(s). 2020 Open Access This article is licensed under a Creative Commons Attribution 4.0 International License, which permits use, sharing, adaptation, distribution and reproduction in any medium or format, as long as you give appropriate credit to the original author(s) and the source, provide a link to the Creative Commons licence, and indicate if changes were made. The images or other third party material in this article are included in the article's Creative Commons licence, unless indicated otherwise in a credit line to the material. If material is not included in the article's Creative Commons licence and your intended use is not permitted by statutory regulation or exceeds the permitted use, you will need to obtain permission directly from the copyright holder. To view a copy of this licence, visit http://creativecommons.org/licenses/by/4.0/. 
In terms of economy, it decelerates the transportation rate of services and goods' merchandising, the consequences of which have to be borne by the consumers in terms of higher prices. Due to the aforementioned facts, there is always a need for an effective methodology that can tackle congestion resulting from the contemporary demand for urban traffic [5].

One of the main purposes of signal timing settings is to move people safely and efficiently through an intersection. Achieving this goal requires an accommodation plan to different users that assign the rightof-way. The plan should be able to adapt according to the fluctuations in demand. Many signal timing parameters affect the performance of the intersection. These parameters include cycle length, green time, change interval, phase sequencing, etc. These parameters are further defined under section 3.1. Regulating the timing of the traffic signals is one of the fastest and most economical ways to curtail congestion at the intersection and improve traffic flow in urban streets. Therefore it is necessary to update the timing of the traffic signal control (TSC) system to cope with the prevailing urban traffic conditions [6-8].

Researchers have been working on the use of numerous approaches for optimizing TST. Several good quality reviews have been written previously within the problem area of TST or TSC settings $[9$, $10]$. are the two most recently published survey papers published in the year 2015, covering different methodological areas utilized until 2014 in this problem field [9]. reviewed the work, concentrating solely on fuzzy logic strategies whereas [10] shed light on fuzzy logic as well as some of the important work of Q-learning, \& neural network approaches used in the domain of TSC setting [5, 11, 12]. are some of the other review papers covering the application of frequently used CI-based methodologies for controlling the flow of traffic at the urban traffic networks. But in terms of technological advancement, the period from January 2015 to January 2020 is huge and significantly important. There is a dearth of a good literature review paper that should cover the literature published in these years regarding TSC and TST settings.

The remainder of this paper is structured as follows. Section 2 describes the research methodology of the paper, section 3 covers the background of the TST while giving the structural design of TST and a review of some frequently used microsimulation tools respectively. Section 4 comprises a classification of TST optimization approaches along with a concise review of the related approaches. The discussion and the analysis of approaches are presented in Section 5, whereas the last section concludes with promising suggestions for future research directions.

\section{Research methodology}

This article analyzes the recent literature for the simulation-optimization, and CI-based approaches for optimizing TST and TSC systems, which have been published from January 2015 to January 2020 in terms of journal papers and conference proceedings. One of the main reasons for covering the research that has been published in the most recent years is technological advancement. These publications were selected by meticulously browsing through databases including Scopus, Web of Science, IEEE Xplore, and Google Scholar. Keywords used to explore the databases were: "TST optimization", "traffic congestion optimization", "TSC settings", "microscopic traffic simulation-based optimization (SimOpt)", "dynamic traffic management system", and "signalized urban intersection". From the reference list of selected publications, further publications were added, which were published in the above mentioned period. Table 1 and Table 2 lists the search parameters used in this study and the total number of papers that we have, respectively.

Table 2 also illustrates the fact that several studies with one of the key phrases, i.e. TST optimization, has seen a significant increase over the past years, due to the continuous advancement in technology and the increasing number of vehicles on urban traffic. In shortlisting, only the studies about TST and TSC have been included, which are either dealing with one of the parameters or the combination of them. These parameters include cycle length of the traffic signal, green phase timing of the traffic signal, offset and phase sequencing of the traffic signal. Studies that are related to the connected vehicles, pedestrians, simulation model calibration, as well as macroscopic and mesoscopic traffic simulation are excluded from this study. Figure 1 illustrates the number of publications included in this study after shortlisting.

The shortlisted publications have been further classified into two categories, that are "microsimulation-based optimization models" and "computational intelligence models". In the 1 st category, papers integrated any one of the microsimulation tools for solving the TST problem with the proposed strategy, are included. Whereas, the papers in the 2nd category uses some sort of an estimation function to evaluate potential solutions during the search process, in the hope of finding an optimal or nearoptimal solution. Some of the papers in this category also employed a microsimulation tool but only 
Table 1 Search parameters of the literature review

\begin{tabular}{|c|c|c|}
\hline Date Range & DataBases & Search Keywords \\
\hline & Scopus & Traffic Signal Timing Optimization, \\
January 2015 -January 2020 & Traffic Congestion Optimization \\
& Teb of Science & Traffic Signals Control Settings \\
& Microscopic Traffic SimOpt \\
& Google Scholars & Dynamic Traffic Management System \\
& & Signalized Urban Intersection \\
\hline
\end{tabular}

for the demonstration of the solution approach (see section 4 for further detail).

Microsimulation tools are frequently used in TST related researches. Our review also shows that approximately $77 \%$ of the papers included in this study utilizes a microsimulation tool. There is a wide range of microsimulation tools available and utilized for research. Therefore, it is useful to include a review, categorization, and comparison of the most commonly used microsimulation tools for future work.

\section{Background on traffic signal timing}

This section sketches out the idea around which the settings and the evaluation of TST and the controllers revolve. In subsection 3.1, we describe the important parameters of TST. Understanding of TSC's structural design is provided in section 3.2. Lastly, section 3.3 presents a critical review of the most commonly used microsimulation tools along with their common and unique features.

\subsection{Traffic signal timing parameters}

One of the main purposes of TST settings is to move people safely and efficiently through an intersection by assigning the right-of-way. Some of the TST setting parameters should be able to adapt to the fluctuations in traffic demand and some should be controlled by the traffic management authority. These control parameters are
- Green Time: The time duration in seconds, during which a given traffic movement at signalized intersection proceed at a saturation flow rate

- Cycle Length: Time required by a signal to complete one cycle.

- Phase Sequence: The order of the signal phases during the signal cycle.

- Change Interval: It is also known as the clearance interval. It is the interval of yellow and red signal timing between phases of traffic signals to provide clearance at an intersection before the onset of conflicting traffic movements.

- Offset: The relationship between coordinated phases in terms of time.

The number of stopped vehicles and the delay can be reduced by increasing the green phase timing for a particular movement. However, an increase in the green time of one traffic movement usually occurs at the expense of increased delay and the number of stopped vehicles in other movements. Therefore, a good signal timing plan is one that allocates time so that overall traffic performance, e.g. average wait delay time, is optimized.

\subsection{Structural Design of Traffic Signal Control}

Traffic signal control (TSC) strategies have been classified into fixed-time, adaptive, and actuated control strategies $[5,13,14]$. The main reason behind this

Table 2 Number of papers covering the literature review keywords per year

\begin{tabular}{|c|c|c|c|c|c|c|c|}
\hline & $\begin{array}{c}\text { TST } \\
\text { Optimization }\end{array}$ & $\begin{array}{c}\text { Traffic } \\
\text { Congestion } \\
\text { Optimization }\end{array}$ & TSC Settings & $\begin{array}{c}\text { Microscopic } \\
\text { Traffic SimOpt }\end{array}$ & $\begin{array}{c}\text { Dynamic Traffic } \\
\text { Management } \\
\text { System }\end{array}$ & $\begin{array}{l}\text { Signalized Urban } \\
\text { Intersection }\end{array}$ & Total \\
\hline 2015 & 78 & 98 & 87 & 35 & 67 & 63 & 428 \\
\hline 2016 & 80 & 114 & 85 & 28 & 83 & 76 & 466 \\
\hline 2017 & 104 & 182 & 98 & 34 & 123 & 70 & 611 \\
\hline 2018 & 106 & 152 & 87 & 26 & 114 & 71 & 556 \\
\hline 2019 & 112 & 160 & 56 & 38 & 76 & 27 & 469 \\
\hline Total & 480 & 706 & 413 & 161 & 463 & 307 & 2530 \\
\hline
\end{tabular}




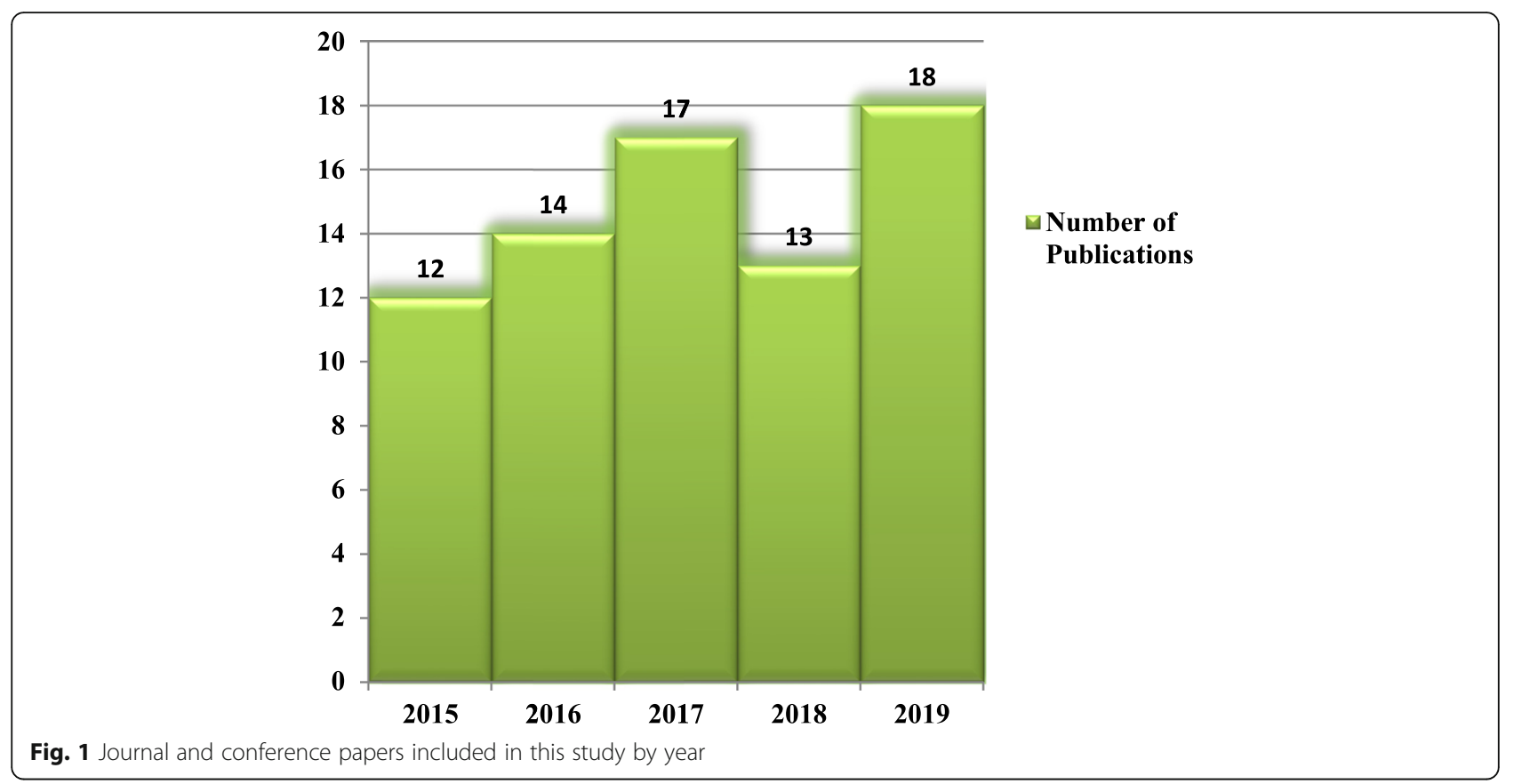

classification is the type of data and the algorithms they employ to optimize traffic signal plan.

Fixed time TSC strategies are mainly appropriate for the traffic signals, where the flow of traffic is somewhat stable and consistent. Based on previously observed traffic data, these strategies make use of offline optimization algorithms for TST and end up with predetermined cycle length, split setting plan. The main objective of this strategy is to achieve an overall goal, such as minimizing average delay, maximizing the capacity of a network, etc. $[15,16]$ developed the initial models, which laid down the foundation of fixed-time traffic control strategies by minimizing the average delay. As the traffic system is exceptionally dynamic in urban areas, any small disturbance in terms of a traffic collision, construction work, etc. can suddenly alter traffic volumes and render the overall performance of a predetermined traffic signal plan insufficient.

On the contrary to fixed-time control strategies, the main aim of the adaptive control strategies is to optimize the TST plan according to the present-time traffic situations in every phase. Hence the use of sensor technologies came into practice. Initial sensor technologies were capable of discerning vehicular presence when they cross it.

Later on, visual systems came into heavy use. The actuated control strategies also use sensors and the actuated controller decides the cycle length based on past information. Whereas the adaptive strategies are the modified form of actuated control, which uses the present data to predict the cycle length of real-time traffic conditions. These sensors are placed at every road within the bounds of the signalized network. However, these strategies cannot perform as much detailed analysis as the fixed time strategies, because they have to regulate traffic signal plans instantly [17].

The traffic systems, especially in urban areas, are exceptionally dynamic. Any small disturbance can suddenly alter traffic volumes. So, it is more beneficial if the system is capable of reducing traffic congestion in real-time. Now in today's world, with the use of sensor technologies and additional strategies, the collection of data in real-time is no more a challenging task. With the abundance of data and the use of available computational power, instant traffic management, or prediction of traffic scenarios can be possible.

\subsection{Review of frequently used microsimulation tools}

Although analytical models are useful in terms of providing insights into more general system behavior, simulation tools have a prominent place in analyzing responses of traffic systems under a variety of conditions. A tool like simulation is very helpful in traffic engineering to analyze the complex dynamic behavior of a traffic stream. Simulation can be defined as the imitation of real-world systems or processes for conveniently acquiring the information through analogous traffic flow models. These models assist in describing the physical propagation of the flow of traffic. The use of traffic simulation models is crucial for a 
comprehensive investigation of the urban transportation system in a safe and suitable environment.

As a whole, traffic simulation can be dichotomized broadly into microscopic and macroscopic approaches. The microscopic simulation approach contemplates the individual behavior of the driver along with the interaction with other vehicles or pedestrians, whereas the macroscopic approach considers the vehicular flow as a whole. Mesoscopic is another approach, which is the hybrid of the previously mentioned approaches. AIMSUN, CORSIM, MATSim, Paramics, SUMO, VISSIM are some of the widely used microsimulation packages for exploring the wide array of dynamic problems in urban traffic. There is a large number of papers included in this study dealing with microsimulation in some form (either evaluation or as a part of the model). Therefore authors at this stage, consider it necessary to discuss the characteristics of some of the most commonly used microsimulation packages for the readers.

Ratrout and Rahman [18] evaluated the attributes and characteristics of various commonly used traffic simulation packages and also provided the relative analysis by focusing on some special features. They found VISSIM, AIMSUN, and CORSIM suitable for modeling features like arterial, freeway congestion, and integrated network of freeways and streets, and AIMSUN, CORSIM, and PARAMICS for intelligent transportation systems (ITS) [19]. compared the results of TransModeler, AIMSUN, and VISSIM at an
International Bridge connecting the US-Mexico border cities.

We categorize and compare the seven most widely used microsimulation tools based on eleven (11) features and present the results in Table 3. Concerning the graphical user interface (GUI), all of the above-mentioned packages are found to be equally user-friendly and adequate. For the lane closures and the modeling of work zones, TransModeler has great advantages over AIMSUN and VISSIM. In terms of the decision modeling of vehicular routing, VISSIM allows easy input of a large amount of data through Excel spreadsheets. AIMSUN, VISSIM, and SUMO are the simulation tools that allow the user to build and control models with an application programming interface (API) by an external programming language. The "AIMSUN Next" by AIMSUN provide the toolkit for the automation of task through programming environment. Whereas, Component Object Model (COM) and Traffic Control Interface $(\mathrm{TraCI})$ are the programming interfaces provided by VISSIM and SUMO respectively. The availability of a hierarchical VISSIM-COM object model makes it easier to code a network with VISSIM as compared to SUMO. Previously AIMSUN did not have any feature of API. One of the most prominent features of AIMSUN Next is its speed, which provides its supremacy to all other current microscopic simulation tools. Saying AIMSUN tried to overcome all of its shortcomings through AIMSUN Next would not be wrong.

Table 3 Classification of most commonly used traffic microsimulation tools

\begin{tabular}{|c|c|c|c|c|c|c|c|}
\hline & CORSIM & MATSim & AIMSUN & Paramics & VISSIM & SUMO & TRANSIMS \\
\hline Open Source & No & Yes & No & No & No & Yes & Yes \\
\hline System & Discrete & Continuous & Continuous & Discrete & Continuous & Continuous & Discrete \\
\hline Visualization & Both & 2D & Both & Both & Both & Both & Both \\
\hline Pedestrian & Yes & No & Yes & Yes & Yes & Yes & No \\
\hline Bus \& Trams & No & No & Yes & Yes & Yes & Yes & No \\
\hline Area of Scope & City/Region & City/Region & $\begin{array}{c}\text { Region/ } \\
\text { Country }\end{array}$ & City/Region & City/Region & City/Region & Country \\
\hline $\begin{array}{c}\text { Output } \\
\text { XML,CSV }\end{array}$ & Text & Graphs & $\begin{array}{c}\text { HTML, } \\
\text { XML. CSV }\end{array}$ & XML & XML & XML \\
\hline $\begin{array}{c}\text { Import Maps } \\
\text { Language }\end{array}$ & N/A & Yes & Yes & N/A & Yes & Yes & N/A \\
\hline $\begin{array}{c}\text { Flexibility in } \\
\text { Infrastructure } \\
\text { Development }\end{array}$ & Limited & Limited & Flexible & Flexible & Flexible & Flexible & Limited \\
\hline \begin{tabular}{c} 
Coding \\
\hline
\end{tabular} & N/A & N/A & Difficult & N/A & Easy & Difficult & N/A \\
\hline
\end{tabular}




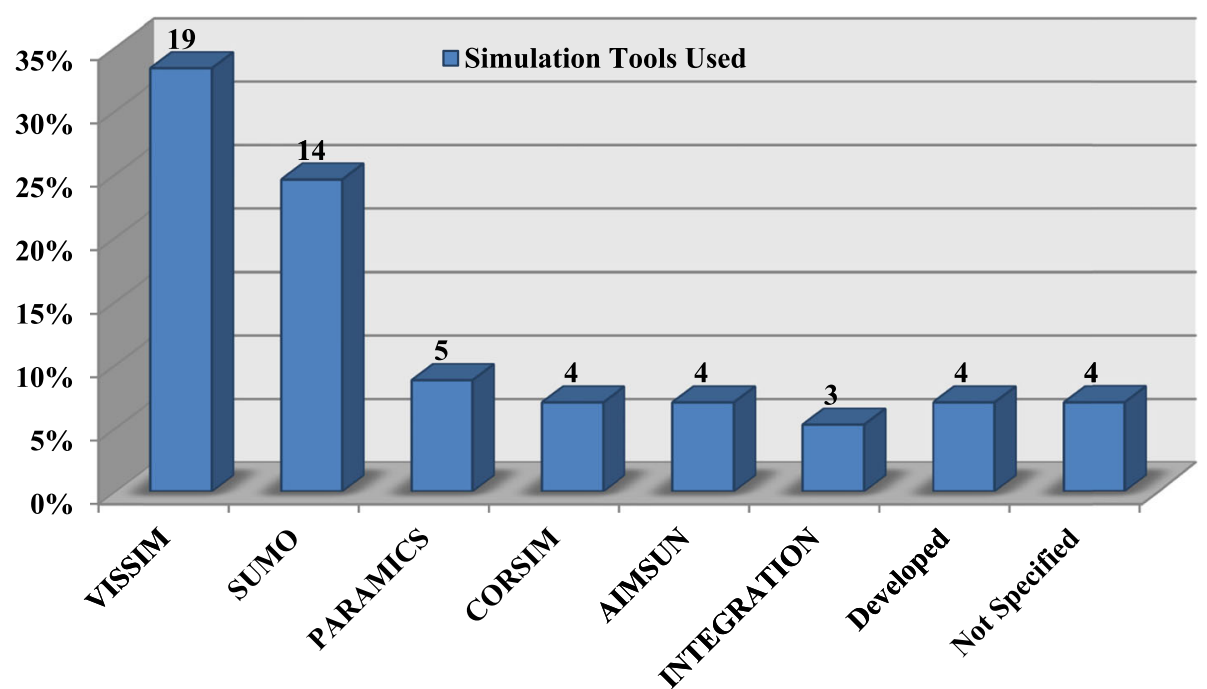

Fig. 2 Number of publications utilizing microsimulation tool

Except for AIMSUN Next, it is recommended that the modeler must have moderate knowledge about programming on Python, $\mathrm{C}++$, or VBA while using VISS $I M$ and SUMO for modeling, otherwise, AIMSUN might be the optimal one. Except for the MatSim, all of the above-mentioned microsimulation tools provide the facility for both 2D and 3D visualization.

Figure 2 indicates that, within the search parameters used in this paper, researchers have chosen VISS $I M$ and SUMO (either for evaluation or as a part of the model) over all other available microsimulation tools in their research published over the last five years. This is a clear proof of the superiority in the usage of both software. The number of times these tools are used is also mentioned at the top of each bar.

\section{Categorization of methodologies for traffic signal timing settings}

Traffic signal control is one of the most efficient methods for urban traffic management, providing a smoother and more secure traffic flow at every intersection. From the time when the simple automatic signal controller has been introduced, the TSC system has been going through interminable improvements to address the factors that cause impediments in TSC. Some of these impediments are inadequate transport infrastructure, an increasing number of vehicles, weather conditions, traffic network structure, etc. Each cause is notable in itself and has the full potential to generate congestion at any time in the network. As a whole, mitigating traffic congestion caused by these reasons is a challenging, complex, and nonlinear stochastic problem for engineers and researchers to solve [5]. In the following subsections, we review traffic signal control papers in two major categories. These are papers utilizing "microSimOpt (MicrosimulationBased Optimization) models" and "computational intelligence (CI) models". Each subsection includes a detailed table summarizing papers belonging to that subsection based on several carefully selected parameters. These parameters are context/objectives, methods and parameters employed, type of intersection studied, control system strategy, source of data, micro-simulation tool used as well as additional comments.

In section 4.1, researches on the SimOpt model with a focus on microscopic traffic simulation are introduced. The analysis of papers using CI methods is given in section 4.2. If one of the studies included in this review can be categorized into more than one (sub)section, it is included in the section based on the most dominant approach.

\subsection{Microsimulation-based optimization model}

SimOpt, in general, is regarded as a field in which the optimization techniques are integrated with simulation analysis [20]. The reason for doing this is to find the best decision variable values among all possibilities without explicitly evaluating (simulating) each possibility [21]. In this sub-section, papers in which a microsimulation tool is integrated with the proposed strategy for solving the TST problem and have been utilized as an evaluation function in an optimization loop are reviewed. Simulation- 
optimization for TST is important because evaluating the effects of minor changes in decision variables regarding TST can be assessed accurately through microsimulation without actual implementation. For understanding the concept; the proposed strategy/algorithm asks the microsimulation model of the network to evaluate the current solution and the results from each simulation run are fed back to the proposed algorithm until some stopping criterion(a). Researchers have used numerous approaches of CI methods along with traffic simulation tools in the domain of TSC. These approaches include but not limited to machine learning approaches, fuzzy logic, and computational strategies such as Evolutionary Computation (EC), Swarm Intelligence (SI), and other population based-metaheuristic algorithms.

Optimization of TST is a complex problem yet cost-effective to mitigate traffic congestion and to smooth the vehicular traffic flow. This optimization problem has been widely addressed in the context of stochastic equilibrium network design with different approaches like deterministic and heuristic methods. Due to the presence of a large number of local optimum points in the convoluted solution space of the problem, deterministic approaches like gradient-based methods are not effective. On the other hand, despite the nonconvex nature of the problem, heuristic approaches like the Genetic Algorithm (GA), Particle Swarm Optimization (PSO) are quite successful in the exploration of the search space. However, they may spend a comparatively long time in finding the global optimum solution. In the next subsections, categorization, and evaluation of recent literature on simulation-optimization based TST approaches are given.

The detailed analysis of the researches published over the past five years is included in Appendix 1 . Below the categorization and evaluation of relevant recent literature based on SimOpt. approaches are presented.

\subsubsection{Artificial intelligence-based approaches}

The papers [22-28] are employed a type of artificial learning algorithm for solving the TST problem. Among these studies, Neural Networks, Adaptive Neuro-Fuzzy Inference System, Q-Learning, fuzzy logic, and Deep Reinforcement learning are the adapted machine learning algorithms. Different objectives have been used in these studies including minimization of average delay [22, 27], total travel time [24, 25], average queue length [26], optimization of TST plan [23], and maximization of the flow rate [28].
Araghi, et al. [22] utilized a different natureinspired algorithm called the cuckoo search algorithm for the first time to tune the parameters of intelligent controller optimally. The Intelligent controllers implemented in this study were a Neural Network $(\mathrm{NN})$ and an Adaptive Neuro-Fuzzy Inference System (ANFIS). The fuzzy logic-based control system developed by Jin, et al. [23] was capable of providing traffic light indication during real-time operations after receiving the messages from the signal controller hardware. The signal control and optimization toolboxes were integrated into the software embedded in the controller's device. In [24] Araghi et al. assessed the performance of three meta-heuristic algorithms, which were Simulated Annealing (SA), GA, and the CS on a complex advanced interval type- 2 adaptive neuro-fuzzy inference system (IT2ANFIS) based traffic signal controller. Miletić et al. [25] compared the effectiveness of two different approaches used in premature traffic light control systems through six different scenarios of microsimulation models using real-time data. The first method used in the comparison was operated by fixed values for vehicle arrival time and queue length ranges, while the second was based on fuzzy logic and, therefore it was more adaptive.

\subsubsection{Metaheuristics based approaches}

Reference numbers [29-34] employ meta-heuristic methods for optimization along with a microsimulation tool. Among the meta-heuristics implementations, population-based methods were mostly employed, where PSO, ACO, and GA are the most heavily utilized methods. In addition to some common objectives that are mentioned in the previous sub(section), Elgarej et al. [32, 33] came up with a different objective of finding the shortest effective green time.

Gökçe et al. [29], Dabiri and Abbas [30], Panovski and Zaharia [31], Chuo et al. [35] utilized PSO for the fulfillment of their objectives. Among them, [29] is the only study that has been carried out for the signalized roundabout containing 28 signal heads, whereas $[30,31]$ worked on optimizing the arterial traffic signals having three intersections and the issues related with traffic flow management in the urban areas respectively. Jintamuttha, et al. [33] proposed a finite-interval model to achieve the objective regarding TST. A different swarm-based algorithm, Bat algorithm, was utilized to relax the computational complexity. Chuo et al. [35] developed a multiple-intersection TST system. PSO with the small adjustment was employed for the consistency of the results. 


\subsubsection{Multi-objective based approaches}

Nguyen et al. [36], Hatri and Boumhidi [37], Zheng et al. [38] are the only papers that employ a multiobjective simulation-optimization approach. Although a relevant approach, there seems to be a research void in implementing multi-objective SimOpt for the TST problem.

Nguyen et al. [36] integrated a local search (LS) algorithm with the iterations of NSGA-II in a way that the output of LS was becoming the next generation's parents in their study. Results of the proposed NSGA-II-LS were compared with NSGA-II and multi-objective differential evolutionary algorithms and found that the proposed algorithm was better than the other two approaches and good simulation results were achievable in the early phase of the optimization procedure. To balance the equity and efficiency of traffic flow in the urban network Zheng et al. [38] presented a bi-objective stochastic SimOpt approach. Two types of surrogate models were also used to capture the mapping relationship between decision variables and objectives. VISSIM was used to model the case study network and the results demonstrated that the proposed model outperformed three other counterparts including NSGA- II.

\subsubsection{Bi-level programming based approaches}

There are only two studies $[39,40]$ that employed a bi-level programming approach, where signal settings are determined by the upper and lower level optimization tasks. With an objective function of maximizing the weighted trip, Hajbabaie and Benekohal in [39] formulated a program to optimize TST and system optimal traffic assignment simultaneously. By relaxing network loading and traffic assignment constraints, the study also proposed a framework for the calculation of the upper-bound value of the objective function.

To obtain the optimal TST setting, Li et al. [40] designed a framework in such a way that the settings of traffic signals were determined by the upper level. The upper level was intended to minimize the average travel time of drivers, whereas the task for achieving the network's equilibrium was attained by the lower level through the settings provided by the upper level.

\subsubsection{Miscellaneous approaches}

References [41-48] employ a mathematical optimization method along with micro-simulation. The methods employed range from dynamic programming to backpressure to optimal control. These approaches are more likely to be useful for design phase problems rather than operational, due to the difficulties involved in solving them for large instances in an acceptable amount of time. Based on a dynamic programming approach with NEMA configuration, the real-time signal control algorithm was formulated by Chen et al. [41]. Dakic et al. [43] also proposed two signal control algorithms based on the backpressure model to maximize throughput through an urban traffic network. These two models were initialized and modified backpressure. Results revealed that the proposed algorithms outperformed the fixed time and actuated control strategies

To deal with the reliable TSC problem, Chen et al. [45] presented an approach in which the higher-order distributional information that was derived from a stochastic microscopic simulator was used. The TSC problem was based on a linear combination of the expectation of total travel time and its standard deviation. For enhancing the computational efficiency of the algorithm, the analytical approximation of the simulated metrics was combined with the simulated data. According to the authors, such kinds of approaches can be utilized to inform the design and operation of the transportation system.

\subsection{Computational intelligence based models}

The researches, which incorporates the CI-based approaches, are analyzed in this section. Papers in this section, use some sort of an estimation function to evaluate potential solutions during the search process, in the hope of finding an optimal or nearoptimal solution. Some of the papers also utilize microsimulation tools. But the usage of microsimulation tools here is not for the development of the proposed solution but rather to demonstrate possible or potential benefits of the proposed solution. In this category, the approaches like fuzzy models, neural networks, machine learning algorithms, evolutionary computation (EC), swarm intelligence (SI), and other population-based metaheuristic algorithms are discussed. Similar to Appendix 1, Appendix 2 presents a detailed analysis of work in this field under the same categories.

One of the strategies to optimize the traffic in urban areas is the use of ITS, which implements the CI method to facilitate problem-solving that previously seemed very difficult. CI is a collection of "intelligence" methods, including evolutionary computing, fuzzy logic, and artificial neural networks with a claim of being the successor of Artificial Intelligence [49]. Moreover, CI can also capitalize on other approaches, like swarm intelligence and reinforcement learning, etc. 
The inspiration for both EC and SI algorithms often comes from nature, like biological evolution. Classical ECs, encompass evolution strategies, evolutionary programming, GA, and genetic programming (GP). They all are metaheuristic optimization techniques for finding the optimal or near-optimal solutions to the nonlinear complex problem within an acceptable time limit. They imitate natural processes, such as natural evolution under the principle of fit or adapted to the environmental condition best, well known as the phenomenon of the survival of the fittest [49]. The origin of SI algorithms is from the behaviors of some social living beings such as birds, ants, and fishes [50]. The main strength of SI based research mainly depends on two families of algorithm namely ant colony optimization and particle swarm optimization. They all are very successful in various kinds of optimization problems.

One of the motivations behind the development of EC was the growing demand for robust automated problem solvers in the second half of the twentieth century, which should apply to a wide range of problems without the need for much tailoring, along with satisfactory performance [51]. Montana et al. [52] presented one of the initial works through an evolutionary approach for intelligent TSC. A hybrid approach of GA and strongly typed GP [53] was employed to optimize fixed cycle signal timings. On the comparison, of both the strategies for three small different network settings, it was found that in all the cases, GP's performance was better than that of GA. These were some details of the preeminent early work that came into the category of CI-based optimization for TST. The detailed summaries of the work that fits with our literature search parameters are given in Appendix 2. This table reflects the diversity of TST optimization in terms of solution methodology and lists the details of recently published research.

Below the categorization and evaluation of relevant recent literature are presented based on CI methods utilized.

\subsubsection{Artificial intelligence-based approaches}

A variety of different AI-based methods [54-61] were used for eliminating bottlenecks or to increase the throughput at the signalized intersections.

Xiang and Chen [54] proposed a Back Propagation neural network-based Grey Qualitative Reinforcement Learning algorithm to eliminate bottlenecks and to avoid reducing traffic flow and timing plan function relationships. Benhamza et al. [55] used a multi-agent framework for the development of an adaptive TST scheme for multiple intersections. In the developed scheme, each intersection was managed by an autonomous agent.

Vidhate et al. [56] and Genders et al. [57] modeled TSC using the RL algorithm based on real-time traffic data whereas Liang et al. [58] proposed a deep RL model to decide the TST and to control the cycle length of traffic signal based on the data collected through different sensors. Ozan et al. [61] presented a modified RL algorithm that was based on QLearning. The algorithm was further combined with Transfyt-7F for finding the optimal TST of the coordinated network. The proposed approach was better than other RL based algorithms because of its ability to produce a sub-environment in each learning event. The similarity in terms of size was kept constant among the new and the original environment using the best solution obtained from the previous learning event.

A decentralized TSC strategy based on the data collected from sensors was introduced by Bemas et al. [59]. A neuroevolution strategy was used to improve the coupling configuration of the introduced $\mathrm{NN}$ and SUMO was employed for the extensive microsimulation based investigation of the proposed model.

\subsubsection{Metaheuristics based approaches}

Metaheuristic approaches are one of the widely implemented by researchers in the optimization of TSC strategies. References [62-75] implemented metaheuristic algorithms such as SI, SA, GA, Bee colony, memetic algorithm, PSO, differential evolution, HS, etc. Our analysis shows that the population-based algorithms are the most widely used metaheuristic algorithms in optimizing TSC strategies.

Li et al. [62] presented a hybrid solution algorithm for arterial TST optimization based on SA and GA. Gao et al. [63] and Gao et al. [72] considered the scheduling of urban traffic light as the model-based optimization problem. To solve this problem, the discrete harmony search algorithm was employed in [63], whereas, five metaheuristics were implemented in [72]. Bie et al. [64], Guo et al. [71] and Tan et al. [65] developed GA to optimize the TST settings of the respective networks and objective functions. Jovanović et al. [66] used the $\mathrm{BC}$ algorithm to solve TST of isolated intersection in an undersaturated and oversaturated traffic conditions.

To control the flow of traffic, Manandhar and Joshi [68] developed a hybrid system that incorporated the Statistical Multiplexing technique and PSO. Based on PSO Tarek et al. [67] also developed a TST control strategy for the signalized roundabout that was combined with the three different sub-controllers. 


\subsubsection{Multi-objective based approaches}

Due to conflict among different objectives of TST optimization, some of the research in the literature considered multi-objective models to optimize the TST problem. References [76-78] refer to the problem of TST optimization with multi-objective models. Optimization of traffic capacity was the common objective among the above-mentioned studies. Other than this, popular objectives were the minimization of vehicle delay, stopping time, and vehicle emission.

$\mathrm{Yu}$ et al. [76] employed a fuzzy compromise programming approach. In this approach, different weight coefficients were assigned to various optimization objectives. These weights could be different depending on the states of the traffic flow ratio. After assigning the weights, the multi-objective function was converted to a single objective which was solved through GA. Zhao et al. [77] and Jia et al. [78] used PSO with some improvement for their multi-objective TST models.

\subsubsection{Dynamic, MILP \& non-linear programming based approaches}

References, [79-83] formulated the TST optimization problem as mixed-integer linear programming (MILP) whereas references $[84,85]$ presented as the non-linear programming models

Countering the oversaturated condition problem of TSC, He et al. [79] introduced the partial grade separation at a signalized intersection. A lane-based optimization model for lane configuration and TST settings was formulated as MILP, which was solved by branch and bound method. Mehrabipour et al. [80] also modeled TST of network-level as MILP. To find the near-optimal TST parameters, a rolling horizon solution methodology was developed. Based on the vehicle trajectory data in urban road networks, Yan et al. [82] formulated a network-level multiband signal coordination scheme as MILP to provide progression bands for major traffic streams. For optimizing TST parameters Köhler et al. [81] presented an approach based on a cyclically time-expanded network model. The model was able to optimize traffic assignment problems at the same time. The MILP model was for optimizing the control parameters.

Mohebifard et al. [84] formulated the network-level TST optimization problem as a Mixed-Integer NonLinear Program (MINLP) which was based on the Cell Transmission Model (CTM) and presented a customized methodology to solve it with a tight optimality gap. $\mathrm{Yu}$ et al. [85] put forward a non-linear programming model for an optimal TSC setting. A new aspect of this model was combining the double queue traffic flow model to the signal-controlled traffic network to record the traffic dynamics and queue spillback in real-time. In [86] a convex (quadratic) programming approach was utilized to optimize the pedestrian as well as vehicular TST at an isolated intersection.

\subsubsection{Miscellaneous approaches}

References [87-100] present miscellaneous approaches to optimize TST settings and TSC strategies. These approaches include stochastic programming, semianalytic, stage-based sequencing, elimination pairing, etc.

A multi-stage stochastic program for the adaptive TSC system, which was based on phase clearance reliability, was proposed by $\mathrm{Ma}$ et al. [87]. In the first stage, a base timing plan that included the cycle length and green timing of each phase was developed, while in the second stage, the green splits and offsets were adapted to the current traffic conditions. Different from the existing methods, Jiao et al. [88] proposed a model that was intended to minimize average delay time per person, rather than the delay of vehicles from traffic intersection. In the first stage, the curves of the accumulative arriving and departing vehicles were fitted and the delay functions of the vehicles were formulated during each phase of the signal. Subsequently, the delay time of the vehicle was shifted to personal delay time, taking into account the passenger load of the vehicles. This personal delay time was further employed as the objective function and proposed a TST optimization model for attaining real-time signal parameters. Simoni et al. [89] introduced a Hamilton-Jacobi formulation to model the TST over the arterial road based on the Lighthill Whitham Richards model.

Keeping the focus on Network Signal Setting Design, Memoli et al. [90] introduced scheduled synchronization. This scheduled synchronization included the scheduling of green phase timing and synchronization to a single optimization problem. The stage-based method was proposed to solve the problem, which was the extension of the synchronization method and the flow model of traffic. Eriskin et al. [91] proposed a new method, elimination pairing system, for designing TST at the oversaturated condition. Afdelghaffar et al. presented the idea of an isolated and adaptable decentralized cycle free TST controller in [92, 93]. The optimization of TST was achieved through the NashBargaining game theory approach. Wu et al. [96] presented a distributed TSC strategy for the traffic lights in the network. Tang et al. [97] formulated a noncentralized TSC paradigm to control phase timing based on fog computing. 


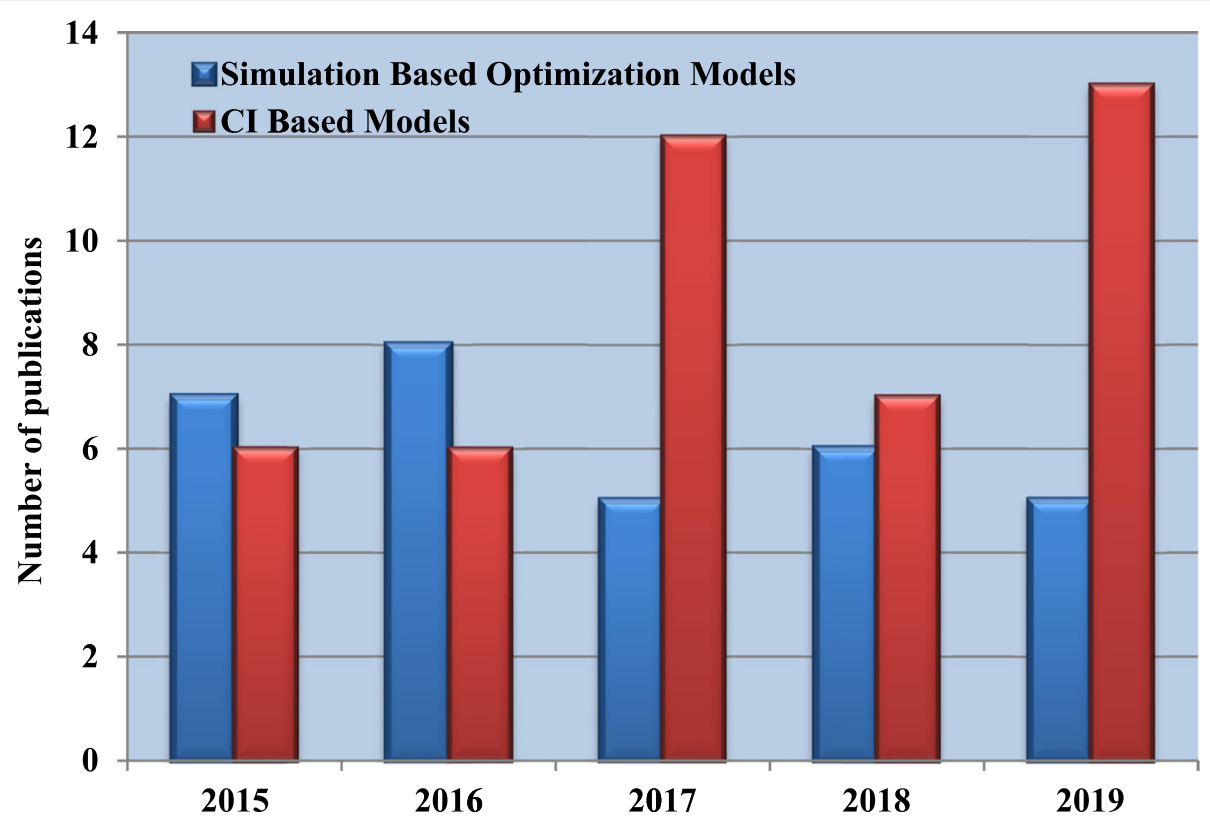

Fig. 3 Publications per year according to the category

\section{Discussion}

\subsection{Analysis of findings}

TST optimization is a difficult and complex problem to solve. It usually involves stochasticity due to the randomness of demand for flow and behavior of players. Realistic problems' solution space is so vast that searching for optimal or near-optimal solutions is a challenging task, to say the least.

Jin et al. [23], Vogel et al [26] developed a fuzzy logic based traffic light controller for an isolated traffic intersection. Results were very encouraging in terms of congestion, travel time, etc. But according to [31, 75] fuzzy logic and machine-learning-based traffic controllers are not economically feasible and require a large investment for their configuration and maintenance. In terms of parameters, it has also been observed that the offset in the network of intersections has been targeted for optimization in a very limited number of studies.

Figure 3 shows that the number of studies using a SimOpt model over the past 5 years is relatively fewer in number. Our analysis shows that the population-based algorithms are the most widely used metaheuristic algorithms in optimizing TSC strategies. In terms of approaches developed for both the control strategies that are fixed time and real-

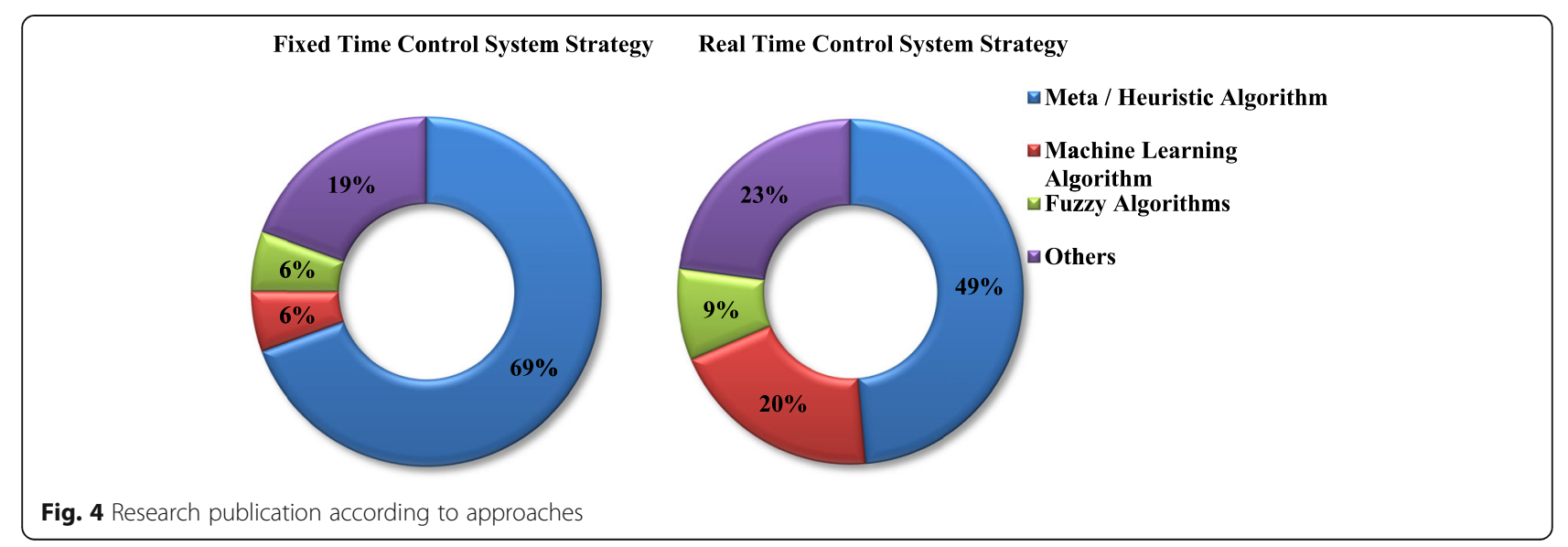


time, the majority of the researchers preferred to work on fixed time controls over the real-time systems. Metaheuristic approaches are utilized mostly for optimization, in $69 \%$ of studies with fixed-time control strategies and $49 \%$ of studies with real-time control strategies. It is also quite clear that the solution to the problem of optimizing TST lies in the real-time traffic control strategy that can deal with the fluctuation of traffic.

We also find out that microsimulation tools are used at an increasing rate. Among the many available microsimulation tools, VISSIM and SUMO have been used in $60 \%$ of the studies either for evaluation or as a part of the model published over the last five years. This is a clear proof of the superiority in the usage of both software.

\subsubsection{Analytical vs simulation-optimization and $\mathrm{Cl}$ methods} As mentioned in section $2,77 \%$ of studies that were analyzed utilized a microsimulation tool. Besides, we have also come across some papers utilizing analytical methods. The search for 2015-2020 resulted in a total of 10 such papers [76, 84, 88, 91, 101-106] utilizing an analytical approach. Only 3 papers [84, $103,105]$ considered a network problem, and the remaining 7 considered a single network problem. But the size of the realistic problems and the amount of interaction that needs to be included in the model for them to be interesting, make use of analytical methods significantly less practical (promising) for TST problems. Analytical models are useful to gain insights into the problem but getting useful results is difficult for two reasons. Either the number of interactions that need to be included in the model or the solution time required, make use of these analytical models prohibitive. For these reasons, analytical models are not included in this review paper.

\subsubsection{Single vs network of intersections}

Traffic is a very much a flow problem. Therefore, it may not be enough to improve traffic at a single intersection or roundabout when the next intersection is blocked. Traffic conditions are very much affected by driver characteristics, roadway conditions, and environmental conditions. Therefore effective TST methods should be able to solve for a network of intersections, representing problematic areas in an urban setting. Our analysis shows that only about $53.5 \%$ of simulation-optimization papers and $54.3 \%$ of CI papers worked on some sort of network of intersections.

\subsubsection{Real-time vs. fixed-time control}

Our analysis finds out that, still a significant amount of research is performed for fixed-time controllers, rather than real-time controllers. Among simulationoptimization methods, $63 \%$ of papers utilized fixedtime compared to $37 \%$ of papers utilizing real-time control. For papers in the CI category, $42 \%$ of papers worked on a fixed-time control problem compared to $58 \%$ of papers on real-time control.

Furthermore, Fig. 4 epitomizes the types of approaches developed for both the control strategies that are fixed time and real-time. We observe the dominance of Metaheuristic approaches in both strategies and machine learning algorithms, especially for real-time control.

\subsubsection{Signalized roundabouts}

Although in many countries, roundabouts used to be non-signalized, more and more countries are adapting signalization of roundabouts led by the UK, France, Sweden, and Turkey [107, 108]. United States Department of Transportation Federal Highway Administration discourages the use of fully signalized roundabouts but also concedes that unexpected demand may require signalization $[109,110]$. In any case, one should expect a significant amount of literature on the signal timing of roundabouts. We have come across only two studies $[29,67]$ on signalized roundabouts.

\subsubsection{Experimentation with realistic conditions}

Testing proposed solution methods to TST is important to truly evaluate its effectiveness. Traffic flow data is complex and presents particular challenges in imitating. That is probably one of the reasons, why there are no well-established data sets that one could test his/her proposed method, like the ones found, e.g. for scheduling problems. For this reason, testing with real-life data is important. From our analysis, we found that about $44.4 \%$ of researches utilizing simulation-optimization methods tested with real-life data compared to about $42.2 \%$ of research utilizing CI methods.

\subsubsection{Evaluation of solutions}

Appendices 1 and 2 list the objective functions used to compare solutions in search of the best. We find out that $61 \%$ of papers use average delay, average travel time, queue length, and flow rate (or some function of them) for this purpose.

\subsection{Implications for practice}

In this subsection, we summarize some of the implications for practice from the analysis of findings. 
Real-time controllers are more flexible to adapt to ever-changing requirements. We believe that fixedtime controllers will have a less practical impact and therefore more research effort can be expected to real-time control strategies.

Working with real-time control strategies, with real data over a large network of intersections all contribute to already high computational requirements for solving TST problems. This means difficulty for analytical approaches and increased utilization of heuristic approaches. There are studies $[7,62,65,69,71$, $96,97]$, especially under the heading of metaheuristicbased approaches (subsection 4.2), that utilize heuristics; though these applications are not enough and most of them found so far, are far away from being extensively customized. In addition, few utilize customized representations and data structures, which can be crucial in performance. Also due to the nature of the traffic problem, the management of a large network of intersections' TST becomes important. We realize larger the network, the more difficult solution or even representation of a solution is.

\section{Conclusion, directions for future research}

Based on the categorization and analysis of state-ofart for TST, the authors propose a number of directions for future research, associated opportunities, and challenges.

Today's urban traffic system comes under great stress during sudden transient peak demand that forms, either with or without prior information. These events diverge from the regular traffic in important characteristics; like being transient, specific to a region, resulting from an emergency, disaster requiring evacuation, or a large public event. Modeling and solution for TST after such events is a research gap that must be filled.

Our analysis found out that only two papers dealing with signalized roundabouts. Roundabouts have a different flow dynamic compared to regular intersections. With the increasing use of signalized roundabouts, especially in metropolitan areas, we believe TST for signalized roundabouts presents a particular research gap within this area.

We found that still less than half of the papers on TST optimization are performed utilizing real-life data. The lack of standardized data sets and the complexity of traffic flow data suggests studies tested with real-life data will have more impact in the field.

Although there are studies made using real-life data and real-time control, there are few or almost no mention of findings and/or methods being applied or adapted in real life. One of the important challenges for the researchers in this area would be getting these methods to the decision-makers and adapters.

Papers studying fixed time controllers are made to set the best possible timings for expected traffic flow. The rest of the studies are made to employ real-time data (either using sensors or cameras) and react to the congestion and try to mitigate the resulting problem.

Recent years have witnessed a significant increase in the advancement of prediction algorithms, computing power, and the availability of real-time data. These facts along with advances in the heuristic algorithms can lead to proactive models, which may now be successfully developed. Proactive models can predict a traffic flow problem before it happens and calculate necessary changes in the TSC system to either prevent it totally or decrease the adverse effects. These proactive models may also be combined with a new area of simulation-optimization. The concept of a digital twin has been gaining popularity for the manufacturing environment. By definition, "Digital twins integrate internet of things, $\mathrm{AI}$, machine learning, and software analytics with spatial network graphs to create living digital simulation models that update and change as their physical counterparts change." [111]. With the aforementioned advances, it is possible and interesting to apply the idea of a digital twin to an urban traffic model. The use of a digital twin for the urban traffic system within the correct framework may enable estimating possible problems earlier and lead to an improvement in the computational power almost real-time.

The great majority of papers found on the relevant topic singles out traffic signal timing and its effects on usually average delay and/or emissions. An important part of heavy traffic intersections, especially in metropolitan areas are pedestrians. Except for [86, 98], pedestrians and the effect of their behavior are not modeled into the studies. The same goes for driver behavior. An important avenue of research would be to analyze the effects of pedestrian and driver behavior on the models.

There is a big increase in the number of studies dealing with autonomous vehicles and technologies. To the best of the author's knowledge, all these studies exclusively study the general area of how autonomous vehicles, flow in traffic safely and/or efficiently and/or environmentally friendly, etc. However, we did not come across studies that benefit from autonomous vehicles and related technologies for TST optimization. A great majority of research on autonomous technologies and TST are studied in rural highway environments, rather than urban. We believe there is a research opportunity to study TST in urban settings with the heavy use of autonomous vehicles. 


\section{Appendix 1}

\subsection{Categorization of existing literature on the SimOpt} mode

\begin{tabular}{|c|c|c|c|c|c|c|c|c|c|c|c|c|c|c|c|c|c|}
\hline \multirow{2}{*}{$\begin{array}{l}\text { Reference } \\
\text { Number }\end{array}$} & \multirow{2}{*}{$\begin{array}{c}\text { Context / } \\
\text { Objective(s) }\end{array}$} & \multirow{2}{*}{ 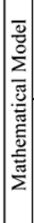 } & \multicolumn{3}{|c|}{ Parameter } & \multicolumn{2}{|c|}{ Intersection } & \multicolumn{2}{|c|}{$\begin{array}{l}\text { Control } \\
\text { System } \\
\text { Strategy }\end{array}$} & \multicolumn{5}{|c|}{ Source of Data } & \multirow{2}{*}{ 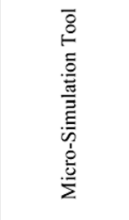 } & \multirow{2}{*}{ 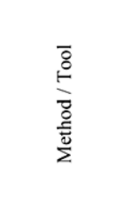 } & \multirow{2}{*}{ Comments } \\
\hline & & & & 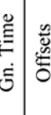 & 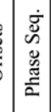 & $\begin{array}{l}\frac{0}{60} \\
\stackrel{5}{=}\end{array}$ & 总 & 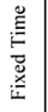 & 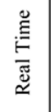 & $\mid$ & $\frac{\partial}{2}$ & 紫 & 䆓产. & 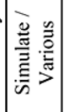 & & & \\
\hline [22] & $\begin{array}{l}\text { - } \downarrow \text { average delay } \\
\text { - Advanced CS } \\
\text { algorithm was } \\
\text { implemented for } \\
\text { the } 1^{\text {st }} \text { time }\end{array}$ & & $v$ & $\checkmark$ & $\checkmark$ & & $\checkmark$ & $\checkmark$ & & & & & & $\checkmark$ & $\begin{array}{l}\text { PARAMIC+ } \\
\text { Matlab }\end{array}$ & $\begin{array}{l}\text { CS-AFNIS } \\
\text { and CS-NN }\end{array}$ & $\begin{array}{l}\text { The results of CS-AFNIS and CS-NN } \\
\text { were compared to the Q-Learning and } \\
\text { fixed time controller and found that the } \\
\text { CS-NN controller was the best, while } \\
\text { CS-AFNIS was second among them }\end{array}$ \\
\hline [23] & • optimize TST plan & & $\mathrm{v}$ & $\checkmark$ & $\checkmark$ & $\checkmark$ & & & $\checkmark$ & $\checkmark$ & & & & & SUMO & Fuzzy Logic. & $\begin{array}{l}\text { An intelligent control system was } \\
\text { developed. }\end{array}$ \\
\hline [24] & - $\downarrow_{\text {total travel time }}$ & & $\checkmark$ & $\checkmark$ & $\checkmark$ & $\checkmark$ & $\checkmark$ & $\checkmark$ & & & & & & $\checkmark$ & PARAMICS & $\mathrm{SA}, \mathrm{GA} \& \mathrm{CS}$ & $\begin{array}{l}\text { Tested three different meta-heuristics in } \\
\text { adaptive neuro-fuzzy inference system } \\
\text { based controller }\end{array}$ \\
\hline [25] & - $\downarrow_{\text {total }}$ travel time & & & $\checkmark$ & $\checkmark$ & $\checkmark$ & & $\checkmark$ & & & & & & $\checkmark$ & $\begin{array}{l}\text { VISSIM+ } \\
\text { Matlab }\end{array}$ & Fuzzy Logic. & $\begin{array}{l}\text { Priority was given to emergency } \\
\text { vehicles }\end{array}$ \\
\hline [26] & $\begin{array}{l}\bullet \downarrow \text { avg. queue } \\
\text { length at } \\
\text { intersection } \\
\end{array}$ & & $\checkmark v$ & $\checkmark$ & $\checkmark$ & $\checkmark$ & & & $\checkmark$ & $\checkmark$ & & & & $\checkmark$ & $\begin{array}{l}\text { VISSIM+ } \\
\text { Matlab }\end{array}$ & Fuzzy Logic. & \\
\hline [27] & $\begin{array}{l}-\downarrow \text { avg. delay at } \\
\text { intersection }\end{array}$ & $\bullet$ & & $\checkmark$ & & $\checkmark$ & & & $\checkmark$ & & $\checkmark$ & & & & SUMO & Deep RL & \\
\hline [28] & $\begin{array}{r}-\uparrow \text { flow rate } \\
\text { through the } \\
\text { intersection }\end{array}$ & - & & $\checkmark$ & & $\checkmark$ & & & $\checkmark$ & & Not $S$ & Specifi & & & Develop & Deep RL & $\begin{array}{l}\text { A vision-based DRL approach was } \\
\text { introduced. }\end{array}$ \\
\hline [29] & $\bullet \downarrow$ avg,travel time & & v & $\checkmark$ & & $\checkmark$ & & $\checkmark$ & & & $\checkmark$ & & & & VISSIM & PSO & $\begin{array}{l}\text { Attempt to solve TST problem for } \\
\text { signalized roundabout }\end{array}$ \\
\hline [30] & - optimize TST plan & & $\checkmark$ & $\checkmark \mid v$ & & & $\checkmark$ & $\checkmark$ & & & Not $S$ & Specifi & & & $\begin{array}{l}\text { VISSIM+ }^{+} \\
\text {Matlab }\end{array}$ & PSO & $\begin{array}{l}\text { A comparison was made with VISTRO } \\
\text { and found it competent for various } \\
\text { states of TST. }\end{array}$ \\
\hline
\end{tabular}

\begin{tabular}{|c|c|c|c|c|c|c|c|c|c|c|c|c|c|c|c|c|c|c|}
\hline \multirow{2}{*}{$\begin{array}{l}\text { Reference } \\
\text { Number }\end{array}$} & \multirow{2}{*}{$\begin{array}{c}\text { Context } / \\
\text { Objective(s) }\end{array}$} & \multirow{2}{*}{ 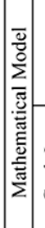 } & \multicolumn{4}{|c|}{ Parameter } & \multicolumn{2}{|c|}{ Intersection } & \multicolumn{2}{|c|}{$\begin{array}{l}\text { Control } \\
\text { System } \\
\text { Strategy }\end{array}$} & \multicolumn{5}{|c|}{ Source of Data } & \multirow{2}{*}{ 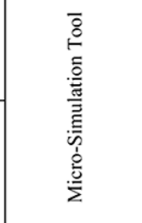 } & \multirow{2}{*}{ 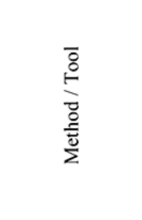 } & \multirow{2}{*}{ Comments } \\
\hline & & & & 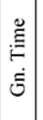 & 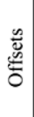 & 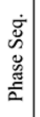 & $\begin{array}{l}\frac{0}{b D} \\
\frac{5}{2}\end{array}$ & 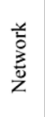 & 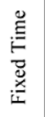 & $\begin{array}{l}\stackrel{\mathscr{n}}{\underline{E}} \\
\stackrel{\widetilde{J}}{\simeq}\end{array}$ & 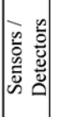 & $\frac{\partial}{\frac{\pi}{0}}$ & 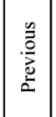 & 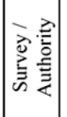 & 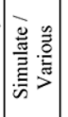 & & & \\
\hline [31] & $\begin{array}{l}-\uparrow \text { flow rate in } \\
\text { minimum time }\end{array}$ & & $\checkmark$ & $\checkmark$ & & & & $\checkmark$ & $\checkmark$ & & & & & & $\checkmark$ & SUMO & PSO & Traffic light system was developed \\
\hline [32] & $\begin{array}{l}\text { - shortest green } \\
\text { period to min. the } \\
\text { time wasted in a } \\
\text { given intersection }\end{array}$ & & & $\checkmark$ & & $\checkmark$ & $\checkmark$ & & & $\checkmark$ & $\checkmark$ & & & & & $\begin{array}{l}\text { Java Agent } \\
\text { Devel. } \\
\text { Environ. }\end{array}$ & $\mathrm{ACO}$ & $\begin{array}{l}\text { A multi-agent control system was } \\
\text { developed. }\end{array}$ \\
\hline [33] & $\begin{array}{l}\downarrow \text { avg. delay at } \\
\text { intersection }\end{array}$ & - & $\checkmark$ & $\checkmark$ & & & $\checkmark$ & & $\checkmark$ & & & & & & $\checkmark$ & SUMO & Bat Algorithm & \\
\hline [34] & $\bullet \downarrow$ avg travel time & & & $\checkmark$ & & & $\checkmark$ & & $\checkmark$ & & & & & & $\checkmark$ & SUMO & $\begin{array}{l}\text { GA \& Hyper- } \\
\text { heuristic } \\
\text { Algorithms }\end{array}$ & $\begin{array}{l}\text { Empirical results showed that GA was } \\
\text { notably performed well over the other } \\
\text { two hyper-heuristic algorithms. }\end{array}$ \\
\hline [35] & $\begin{array}{l}-\begin{array}{l}\downarrow \text { queue length at } \\
\text { intersection }\end{array} \\
\end{array}$ & & $\checkmark$ & $\checkmark$ & $\checkmark$ & & $\checkmark$ & & $\checkmark$ & & & $\checkmark$ & $\checkmark$ & $\checkmark$ & & Not Specified & PSO & $\begin{array}{l}\text { A significant reduction in the queue } \\
\text { length was observed at a congested } \\
\text { intersection. }\end{array}$ \\
\hline [36] & $\begin{array}{l}-\downarrow \text { avg. delay at the } \\
\text { intersection } \\
-\downarrow \downarrow \text { queue length at } \\
\text { the intersection } \\
-\downarrow \downarrow \text { avg. travel time } \\
-\downarrow \text { travel cost etc. } \\
\end{array}$ & $\bullet$ & $\checkmark$ & $\checkmark$ & $\checkmark$ & $\checkmark$ & & $\checkmark$ & & $\checkmark$ & & & Speci & ified & & SUMO & $\begin{array}{l}\text { NSGA-II+ LS, } \\
\text { NSGA-II \& } \\
\text { MODEA }\end{array}$ & $\begin{array}{l}\text { Multi-objective optimization strategy } \\
\text { (NSGA-II+ LS) was proposed }\end{array}$ \\
\hline [37] & $\begin{array}{l}\text { - } \uparrow \text { flow rate } \\
\text { - } \downarrow \text { avg. delay }\end{array}$ & & & $\checkmark$ & & & & $\checkmark$ & $\checkmark$ & & & & Speci & ified & & SUMO & $\begin{array}{l}\text { Q-learning }+ \\
\text { PSO }\end{array}$ & $\begin{array}{l}\text { An intelligent multi-objective control } \\
\text { system was developed }\end{array}$ \\
\hline [38] & $\begin{array}{l}\text { - optimize TST plan } \\
\text { - environmental } \\
\text { concerns }\end{array}$ & $\bullet$ & & $\checkmark$ & & $\checkmark$ & & $\checkmark$ & & $\checkmark$ & $\checkmark$ & & & & & VISSIM & $\begin{array}{l}\text { Regressing } \\
\text { Kriging model } \\
+ \text { BOSSO }\end{array}$ & $\begin{array}{l}\text { The proposed methodology was } \\
\text { validated to outperform three other } \\
\text { counterparts including NSGA- II. }\end{array}$ \\
\hline [39] & $\begin{array}{l}\text { - optimize TST } \\
\text { parameters for } \\
\text { over-saturated } \\
\text { states }\end{array}$ & - & & $\checkmark$ & $\checkmark$ & $\checkmark$ & & $\checkmark$ & $\checkmark$ & & & $\checkmark$ & & & $\checkmark$ & CORSIM & GA & $\begin{array}{l}\text { Solve traffic assignment problem } \\
\text { simultaneously }\end{array}$ \\
\hline
\end{tabular}




\begin{tabular}{|c|c|c|c|c|c|c|c|c|c|c|c|c|c|c|c|c|c|}
\hline \multirow{2}{*}{$\begin{array}{l}\text { Reference } \\
\text { Numbe }\end{array}$} & \multirow{2}{*}{$\begin{array}{c}\text { Context// } \\
\text { Objective(s) }\end{array}$} & \multirow{2}{*}{ 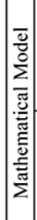 } & \multicolumn{3}{|c|}{ Parameter } & \multicolumn{2}{|c|}{$\begin{array}{l}\text { Intersect } \\
\text { ion }\end{array}$} & \multicolumn{2}{|c|}{$\begin{array}{l}\text { Control } \\
\text { System } \\
\text { Strategy }\end{array}$} & \multicolumn{5}{|c|}{ Source of Data } & \multirow{2}{*}{ 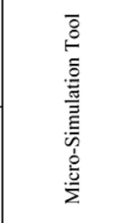 } & \multirow{2}{*}{ 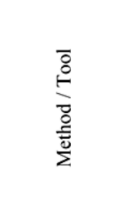 } & \multirow{2}{*}{ Comments } \\
\hline & & & 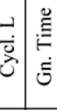 & 量 & 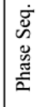 & 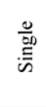 & $\begin{array}{l}\text { 产 } \\
\text { 离 } \\
\text { Z }\end{array}$ & 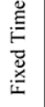 & 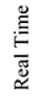 & 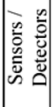 & : & 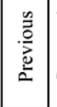 & 﨎高 & 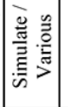 & & & \\
\hline [40] & $\bullet \downarrow$ avg travel time & - v & $\checkmark v$ & $\checkmark$ & $\checkmark$ & & $\checkmark$ & $\checkmark$ & & \multicolumn{5}{|c|}{ Not Specified } & SUMO & GA & $\begin{array}{l}\text { A bi-level optimization framework for } \\
\text { TSC was proposed. }\end{array}$ \\
\hline [41] & $\begin{array}{l}-\checkmark \text { queue length at } \\
\text { the intersection } \\
-\downarrow \text { avg. delay at an } \\
\text { intersection } \\
-\uparrow \text { flow rate }\end{array}$ & - $v$ & $\checkmark v$ & & $\checkmark$ & $\checkmark$ & & & $\checkmark$ & $\checkmark$ & & & & & VISSIM & $\begin{array}{c}\text { Dynamic } \\
\text { Programming }\end{array}$ & $\begin{array}{l}\text { Synchro was employed for acquiring } \\
\text { optimize signal timing for the base } \\
\text { scenario. }\end{array}$ \\
\hline [42] & $\begin{array}{l}- \text { improve overall } \\
\text { traffic network }\end{array}$ & $\bullet$ & $\checkmark$ & & $\checkmark$ & & $\checkmark$ & & $\checkmark$ & $\checkmark$ & & & & $\checkmark$ & CORSIM & & $\begin{array}{l}\text { The proposed system having the } \\
\text { capability to deal with various } \\
\text { conditions of congestions. The priority } \\
\text { was given to transit signals to improve } \\
\text { vehicular productivity of the network. }\end{array}$ \\
\hline [43] & $\begin{array}{l}-\uparrow \text { flow rate } \\
\text { through the } \\
\text { network }\end{array}$ & & $\checkmark v$ & $\checkmark$ & & & $\checkmark$ & $\checkmark$ & & & $\checkmark$ & & & & VISSIM & Back Pressure & $\begin{array}{l}\text { Results revealed that the proposed } \\
\text { algorithms outperformed the fixed time } \\
\text { and actuated control strategies. }\end{array}$ \\
\hline [44] & $\begin{array}{l}-\downarrow \text { congestion in the } \\
\text { urban network }\end{array}$ & & & & $\checkmark$ & & $\checkmark$ & & $\checkmark$ & $\checkmark$ & & & & & VISSIM & UTOPIA & $\begin{array}{c}\text { Testing UTOPIA (Urban Traffic } \\
\text { Optimization by Integrated } \\
\text { Automation) through microsimulation. }\end{array}$ \\
\hline [45] & • optimize TST plan & $\bullet$ & $\checkmark$ & & $\checkmark$ & & $\checkmark$ & $\checkmark$ & & & & & & $\checkmark$ & Not Specified & $\begin{array}{l}\text { Higher-Order } \\
\text { Distri- } \\
\text { Butional } \\
\text { Information }\end{array}$ & \\
\hline
\end{tabular}

\begin{tabular}{|c|c|c|c|c|c|c|c|c|c|c|c|c|c|c|c|c|c|c|}
\hline \multirow{2}{*}{$\begin{array}{l}\text { Reference } \\
\text { Numbe }\end{array}$} & \multirow{2}{*}{$\begin{array}{l}\text { Context / } \\
\text { Objective(s) }\end{array}$} & \multirow{2}{*}{ 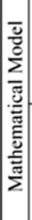 } & \multicolumn{4}{|c|}{ Parameter } & \multicolumn{2}{|c|}{$\begin{array}{l}\text { Intersect } \\
\text { ion }\end{array}$} & \multicolumn{2}{|c|}{$\begin{array}{l}\text { Control } \\
\text { System } \\
\text { Strategy }\end{array}$} & \multicolumn{5}{|c|}{ Source of Data } & \multirow{2}{*}{ 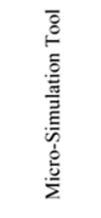 } & \multirow{2}{*}{ 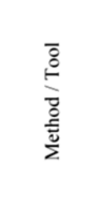 } & \multirow{2}{*}{ Comments } \\
\hline & & & & $\begin{array}{l}\stackrel{0}{E} \\
\dot{E} \\
\dot{\Xi}\end{array}$ & 号 & 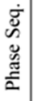 & $\begin{array}{l}\frac{0}{60} \\
\frac{5}{5}\end{array}$ & 总 & 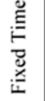 & 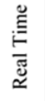 & 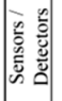 & 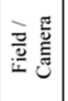 & $\frac{0}{\frac{0}{2}}$ & 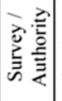 & 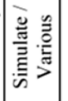 & & & \\
\hline [46] & $\begin{array}{l}-\downarrow \text { traffic } \\
\text { congestion }\end{array}$ & $\bullet$ & & $\checkmark$ & & $\checkmark$ & & $\checkmark$ & & $\checkmark$ & & & $\checkmark$ & & & AIMSUN & $\begin{array}{c}\text { HJB } \\
\text { Optimality } \\
\text { Equation }\end{array}$ & $\begin{array}{l}\text { The proposed strategy was able to } \\
\text { adapt w.r.t the different traffic } \\
\text { conditions and provide adequate trade } \\
\text { off among computational complexity } \\
\text { and performance of the network }\end{array}$ \\
\hline [47] & $\begin{array}{l}-\downarrow \text { traffic } \\
\text { congestion }\end{array}$ & & \begin{tabular}{l|l} 
\\
\end{tabular} & $\checkmark$ & & & $\checkmark$ & & $\checkmark$ & & & $\checkmark$ & & & & VISSIM & & $\begin{array}{l}\text { Performance evaluation of signalized } \\
\text { roundabout vs four-way intersection. }\end{array}$ \\
\hline [48] & $\bullet$ optimize TST plan & $\bullet$ & & $\checkmark$ & $v$ & $\checkmark$ & & r & $\checkmark$ & & & r & & & & VISSIM & BOSSO & $\begin{array}{l}\text { The proposed methodology was } \\
\text { validated to outperform three other } \\
\text { counterparts including NSGA-II. }\end{array}$ \\
\hline
\end{tabular}

\begin{tabular}{|c|c|c|}
\hline $\begin{array}{l}\text { Legends: } \\
\uparrow \uparrow \text { : Maximize } \\
\downarrow \text { : Minimize } \\
\text { : Dealt With } \\
\text { : Available } \\
\text { \#: Number of } \\
\text { Cycl. L. Cycle Length } \\
\text { Gin. Time Green Time } \\
\text { Phase Seg.: Phase Sequence }\end{array}$ & $\begin{array}{l}\text { GA: Genctic Algorithm } \\
\text { HS: Harmony Search } \\
\text { RL: Reinforcement Learning } \\
\text { AFNIS: Adaptive Neuro-Fuzzy Inference System } \\
\text { NN: Neural Network } \\
\text { NSGA-lII Non-dominated Sorting GA } \\
\text { CS: Cuckoo Scarch } \\
\text { SA: Simulated Annealing } \\
\text { DE: Differential Evolution }\end{array}$ & 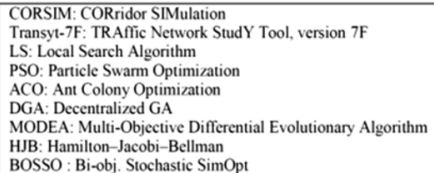 \\
\hline
\end{tabular}




\section{Appendix 2}

\subsection{Categorization of existing literature on $\mathrm{Cl}$ based model}

The researchers from the transportation field working in the area of TST are moving towards the implementation of hybrid algorithms. The main idea behind this is to overcome flaws in one algorithm, especially to reduce complexity and speed up the processes so that they can be more useful in optimizing TST. Sign of addition i.e. "+" between the two different strategies in the "Method / Tool" column of summary in Appendix 2 showing the hybrid of those two strategies, like $[62,75]$ presented the hybrid of SAGA and TS-ABC based algorithms respectively for solving the problem. Additionally, the table also indicates whether the results generated from the underexamined strategy is verified by any simulation means or not.

\begin{tabular}{|c|c|c|c|c|c|c|c|c|c|c|c|c|c|c|c|c|c|}
\hline \multirow{2}{*}{$\begin{array}{l}\text { Reference } \\
\text { Number }\end{array}$} & \multirow{2}{*}{$\begin{array}{l}\text { Context/ } \\
\text { Objective(s) }\end{array}$} & \multirow{2}{*}{ 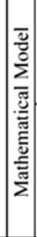 } & \multicolumn{3}{|c|}{ Parameter } & \multicolumn{2}{|c|}{ Intersection } & \multicolumn{2}{|c|}{$\begin{array}{l}\text { Control } \\
\text { System } \\
\text { Strategy }\end{array}$} & \multicolumn{5}{|c|}{ Source of Data } & \multirow{2}{*}{ 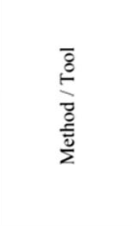 } & \multirow{2}{*}{ 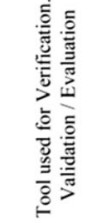 } & \multirow{2}{*}{ Comment } \\
\hline & & & 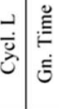 & $\frac{n}{2}$ & 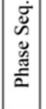 & $\begin{array}{l}\frac{0}{0 D} \\
\frac{D}{2}\end{array}$ & 兑 & 总 & 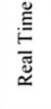 & 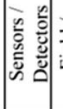 & 吾竞 & 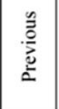 & 恶言 & 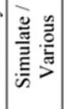 & & & \\
\hline [7] & - optimize TST plan & & $\checkmark$ & & & & $\checkmark$ & $\checkmark$ & & $\checkmark$ & & & & & $\begin{array}{l}\text { Memetic } \\
\text { Algorithm }\end{array}$ & AIMSUN & $\begin{array}{l}\text { Results demonstrate that the proposed } \\
\text { algorithm was better than GA and } \\
\text { traditional fixed-time TST settings. }\end{array}$ \\
\hline [54] & $\begin{array}{l}-\downarrow \text { congestion in } \\
\text { bottleneck region }\end{array}$ & & $\checkmark$ & & $\checkmark$ & & $\checkmark$ & & r & $\checkmark$ & & & & & Grey RL & VISSIM & $\begin{array}{l}\text { Grey RL was based on Back } \\
\text { Propagation NN. }\end{array}$ \\
\hline [55] & $\begin{array}{l}-\uparrow \text { flow rate } \\
\text { through the } \\
\text { intersection }\end{array}$ & & & & & & $\checkmark$ & & $\checkmark$ & $\checkmark$ & & & & & $\begin{array}{l}\text { Multi-Agent } \\
\text { Optimization }\end{array}$ & SUMO & $\begin{array}{l}\text { Found that the model can maximize the } \\
\text { throughput by mitigating the } \\
\text { congestions in the whole network. }\end{array}$ \\
\hline [56] & $\begin{array}{l}-\downarrow \text { avg. delay at } \\
\text { intersection }\end{array}$ & & $\checkmark$ & & & $\checkmark$ & & & $\checkmark$ & & & & & $\checkmark$ & $\mathrm{RL}$ & & $\begin{array}{l}\text { The model was found good in learning } \\
\text { from complex systems but required } \\
\text { lengthy duration to entire learning. }\end{array}$ \\
\hline [57] & 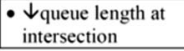 & & $\checkmark$ & & $\checkmark$ & $\checkmark$ & & & $\checkmark$ & $\checkmark$ & & & & & $\mathrm{RL}$ & SUMO & \\
\hline
\end{tabular}




\begin{tabular}{|c|c|c|c|c|c|c|c|c|c|c|c|c|c|c|c|c|c|c|}
\hline \multirow{2}{*}{$\begin{array}{l}\text { Reference } \\
\text { Number }\end{array}$} & \multirow{2}{*}{$\begin{array}{c}\text { Context / } \\
\text { Objective(s) }\end{array}$} & \multirow{2}{*}{ 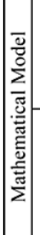 } & \multicolumn{4}{|c|}{ Parameter } & \multicolumn{2}{|c|}{ Intersection } & \multicolumn{2}{|c|}{$\begin{array}{l}\text { Control } \\
\text { System } \\
\text { Strategy }\end{array}$} & \multicolumn{5}{|c|}{ Source of Data } & \multirow{2}{*}{ 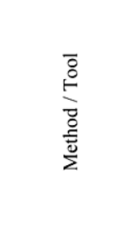 } & \multirow{2}{*}{ 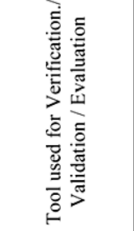 } & \multirow{2}{*}{ Comment } \\
\hline & & & 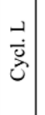 & 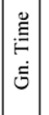 & 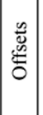 & 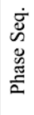 & $\begin{array}{l}\frac{0}{b D} \\
\frac{D}{5}\end{array}$ & 产 & 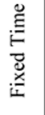 & 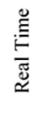 & 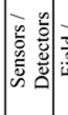 & 吾 & $\frac{0}{2}$ & 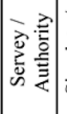 & 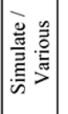 & & & \\
\hline [58] & - control TST & & $\checkmark$ & r & & & $\checkmark$ & & & $\checkmark$ & $\checkmark$ & & & & & Deep RL & SUMO & $\begin{array}{l}\text { The double Q-learning network was put } \\
\text { forward to manage the complex traffic } \\
\text { scenario }\end{array}$ \\
\hline [59] & - $\downarrow_{\text {total travel time }}$ & & $\checkmark$ & $\checkmark r$ & & & & $\checkmark$ & & $\checkmark$ & $\checkmark$ & & & & & $\begin{array}{l}\text { Neuro- } \\
\text { Evolution } \\
\text { strategy }\end{array}$ & SUMO & $\begin{array}{l}\text { The priorities of traffic streams were } \\
\text { evaluated by the controller with the use } \\
\text { of ensemble artificial NN. }\end{array}$ \\
\hline [60] & $\begin{array}{l}-\downarrow_{\text {total cumulative }} \\
\text { delay }\end{array}$ & & & $\checkmark$ & r & & $\checkmark$ & $\checkmark$ & & $\checkmark$ & & $\checkmark$ & & $\checkmark$ & & RL & PARAMICS & $\begin{array}{l}\text { Two multi-agent RL based model for } \\
\text { independent \& coordinated intersection } \\
\text { environment were assessed. }\end{array}$ \\
\hline [61] & - optimize TST plan & $\bullet$ & $\checkmark$ & $\checkmark$ & $\checkmark$ & & & $\checkmark$ & $\checkmark$ & & \multicolumn{5}{|c|}{ Not Specified } & Modified RL & Transyt-7F & $\begin{array}{l}\text { Tested on medium-sized signalize } \\
\text { network. Comparisons were made with } \\
\text { GA \& HS }\end{array}$ \\
\hline [62] & - optimize green & & $\checkmark$ & $\checkmark$ & & $\checkmark$ & & $\checkmark$ & $\checkmark$ & & & $\checkmark$ & & $\checkmark$ & & $\mathrm{SA}+\mathrm{GA}$ & & $\begin{array}{l}\text { NEMA phase structure was kept under } \\
\text { consideration }\end{array}$ \\
\hline [63] & $\begin{array}{c}\bullet \downarrow \text { network-wise } \\
\text { total delay time }\end{array}$ & $\bullet$ & & $\checkmark$ & & & & $\checkmark$ & & $\checkmark$ & \multicolumn{5}{|c|}{ Not Specified } & Discrete HS & & $\begin{array}{l}\text { To improve the performance of the } \\
\text { algorithm, a novel strategy of using } \\
\text { three search operator with different } \\
\text { structures were proposed. }\end{array}$ \\
\hline [64] & $\begin{array}{l}\bullet \text { avg. delay at } \\
\text { intersection }\end{array}$ & $\bullet$ & $\checkmark$ & $\checkmark$ & & $\checkmark$ & $\checkmark$ & & $\checkmark$ & & & & & $\checkmark$ & & GA & & $\begin{array}{l}\text { Analyzed the spillback phenomenon of } \\
\text { the hook turn traffic control scheme } \\
\text { and proposed the nonlinear integer } \\
\text { programming model for the optimal } \\
\text { TST }\end{array}$ \\
\hline [65] & $\begin{array}{l}-\downarrow_{\text {avg. network }} \\
\text { delay }\end{array}$ & & & $\checkmark$ & & $\checkmark$ & & $\checkmark$ & $\checkmark$ & & \multicolumn{5}{|c|}{ Not Specified } & DGA & Matlab m-file & \\
\hline
\end{tabular}

\begin{tabular}{|c|c|c|c|c|c|c|c|c|c|c|c|c|c|c|c|c|c|c|}
\hline \multirow{2}{*}{$\begin{array}{l}\text { Reference } \\
\text { Number }\end{array}$} & \multirow{2}{*}{$\begin{array}{l}\text { Context// } \\
\text { Objective(s) }\end{array}$} & \multirow{2}{*}{ 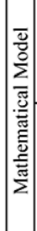 } & \multicolumn{4}{|c|}{ Parameter } & \multicolumn{2}{|c|}{ Intersection } & \multicolumn{2}{|c|}{$\begin{array}{l}\text { Control } \\
\text { System } \\
\text { Strategy }\end{array}$} & \multicolumn{5}{|c|}{ Source of Data } & \multirow{2}{*}{ 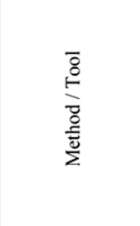 } & \multirow{2}{*}{ 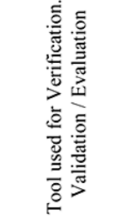 } & \multirow{2}{*}{ Comment } \\
\hline & & & & 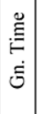 & 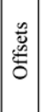 & 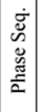 & 竞 & 产 & 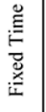 & 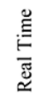 & $\mid$ & 证 & 鵕 & 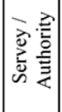 & 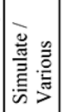 & & & \\
\hline [66] & $\begin{array}{l}-\downarrow \text { avg. control } \\
\text { delay at the } \\
\text { intersection } \\
\end{array}$ & $\bullet$ & $\checkmark$ & $\checkmark$ & & & $\checkmark$ & & $\checkmark$ & & & & & & $\checkmark$ & $\mathrm{BC}$ & & \\
\hline [67] & $\begin{array}{l}\bullet \downarrow \text { overall travel } \\
\text { time } \\
\bullet \downarrow \text { delay time }\end{array}$ & & $\checkmark$ & $\checkmark$ & & & & $\checkmark$ & & $\checkmark$ & $\checkmark$ & & & & & $\begin{array}{l}\mathrm{PSO}+\text { three } \\
\text { Sub- } \\
\text { Controllers }\end{array}$ & & $\begin{array}{l}\text { Presented the TSC strategy for the } \\
\text { signalized roundabout. }\end{array}$ \\
\hline [68] & $\begin{array}{l}-\underset{\text { avg. delay at }}{ } \\
\text { intersection }\end{array}$ & & & $\checkmark$ & & $\checkmark$ & $\checkmark$ & & & $\checkmark$ & $\checkmark$ & & & $\checkmark$ & & $\begin{array}{l}\text { Statistical } \\
\text { Multiplexing }+ \\
\text { PSO }\end{array}$ & SUMO & $\begin{array}{l}\text { An intelligent control system was } \\
\text { developed using Statistical } \\
\text { Multiplexing }\end{array}$ \\
\hline [69] & - $\downarrow$ avg total delay & & & $\checkmark$ & & & & $\checkmark$ & & $\checkmark$ & \multicolumn{5}{|c|}{ Provided by the authority. } & GA \& DE & AIMSUN & $\begin{array}{l}\text { Comparison of GA \& DE based active } \\
\text { traffic controller was made }\end{array}$ \\
\hline [70] & $\begin{array}{l}\text { - TST model for } \\
\text { two-phase } \\
\text { intersection }\end{array}$ & - & & $\checkmark$ & & & $\checkmark$ & & $\checkmark$ & & & $\checkmark$ & & & & $\mathrm{GA}$ & VISSIM & $\begin{array}{l}\text { TRANSYT-7F was used to validate the } \\
\text { model. - }\end{array}$ \\
\hline [71] & $\begin{array}{l}-\downarrow \text { the product of } \\
\text { total travel time } \\
\text { and the variance of } \\
\text { travel time of unit } \\
\text { mileage associated } \\
\text { with area-wide } \\
\text { traffic intersection. }\end{array}$ & $\bullet$ & $\checkmark$ & $\checkmark$ & $\checkmark$ & & & $\checkmark$ & & $\checkmark$ & $\checkmark$ & & & & & GA & PARAMICS & \\
\hline [72] & $\begin{array}{l}\text { - the total network- } \\
\text { wide delay time of } \\
\text { all the vehicles }\end{array}$ & $\bullet$ & $\checkmark$ & $\checkmark$ & & & & $\checkmark$ & $\checkmark$ & & & & Speci & ified & & $\begin{array}{c}\text { GA, Artificial } \\
\text { BC, HS, Jaya } \\
\text { and Water } \\
\text { Cycle } \\
\text { Algorithm } \\
\end{array}$ & & $\begin{array}{l}\text { Five different heuristics were compared } \\
\text { along with LS. Results revealed that the } \\
\text { performance of ABC-LS was better. }\end{array}$ \\
\hline [73] & $\begin{array}{l}-\downarrow \text { avg. delay at } \\
\text { intersection } \\
\text { \avg. \# stops } \\
-\uparrow \text { effective } \\
\text { capacity }\end{array}$ & $\bullet$ & $\checkmark$ & $\checkmark$ & & & $\checkmark$ & & & $\checkmark$ & & $\checkmark$ & & & & $\begin{array}{l}\text { PSO based on } \\
\text { Pareto front }\end{array}$ & & $\begin{array}{l}\text { Pareto front based multi-objective TSC } \\
\text { model using PSO was presented. }\end{array}$ \\
\hline
\end{tabular}




\begin{tabular}{|c|c|c|c|c|c|c|c|c|c|c|c|c|c|c|c|c|}
\hline \multirow{2}{*}{$\begin{array}{l}\text { Reference } \\
\text { Number }\end{array}$} & \multirow{2}{*}{$\begin{array}{c}\text { Context / } \\
\text { Objective(s) }\end{array}$} & \multirow{2}{*}{ 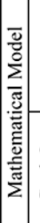 } & \multicolumn{4}{|c|}{ Parameter } & \multicolumn{2}{|c|}{ Intersection } & \multicolumn{2}{|c|}{$\begin{array}{l}\text { Control } \\
\text { System } \\
\text { Strategy }\end{array}$} & \multicolumn{3}{|c|}{ Source of Data } & \multirow{2}{*}{ 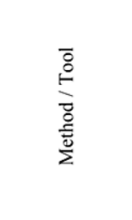 } & \multirow{2}{*}{ 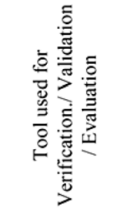 } & \multirow{2}{*}{ Comment } \\
\hline & & & 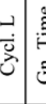 & & & 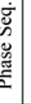 & $\begin{array}{l}\frac{0}{00} \\
\text { 部 }\end{array}$ & $\begin{array}{l}\text { 产 } \\
\text { 产 } \\
\text { ż }\end{array}$ & 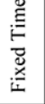 & 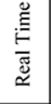 & 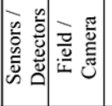 & 总 & 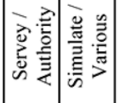 & & & \\
\hline [74] & $\begin{array}{l}-\downarrow \text { avg. delay at } \\
\text { intersections }\end{array}$ & & $\checkmark v$ & $\checkmark$ & $\checkmark$ & & & $\checkmark$ & & $\checkmark$ & \multicolumn{3}{|c|}{ Not Specified } & Adaptive GA & Not Specified & $\begin{array}{l}\text { A computing platform was utilized for } \\
\text { simulation. }\end{array}$ \\
\hline [75] & $\begin{array}{l}\text { - } \downarrow \text { avg. delay and } \\
\text { mean sq. error of } \\
\text { avg. delay at } \\
\text { intersection }\end{array}$ & • & $\mathrm{s}$ & $\checkmark$ & & 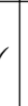 & $\checkmark$ & & $\checkmark$ & & \multicolumn{3}{|c|}{ Not Specified } & TS-ABC & Not Specified & \\
\hline [76] & $\begin{array}{l}\text { - } \uparrow \text { traffic capacity } \\
-\downarrow \text { vehicle cycle } \\
\text { delay } \\
-\downarrow \text { vehicle stop } \\
\text { - exhaust emission }\end{array}$ & - $v$ & $\checkmark v$ & 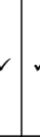 & $\checkmark$ & & $\checkmark$ & & $\checkmark$ & & \multicolumn{3}{|c|}{ Not Specified } & GA & VISSIM & \\
\hline [77] & $\begin{array}{l}-\downarrow \text { avg. vehicle } \\
\text { delay } \\
\bullet \downarrow \text { slow traffic } \\
\text { delay } \\
\bullet \downarrow \text { vehicle stopping } \\
\text { times } \\
-\uparrow \text { traffic capacity. }\end{array}$ & $\bullet$ & $\checkmark v$ & $\checkmark$ & & $\checkmark$ & $\checkmark$ & & $\checkmark$ & & \multicolumn{3}{|c|}{ Not Specified } & PSO & & $\begin{array}{l}\text { A multi-objective optimization } \\
\text { algorithm was developed. }\end{array}$ \\
\hline [78] & $\begin{array}{l}-\downarrow \text { vehicle } \\
\text { emission } \\
-\uparrow \text { capacity of an } \\
\text { intersection } \\
-\downarrow \text { per capita delay. }\end{array}$ & • $v$ & $\checkmark$ & 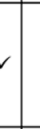 & & $\checkmark$ & $\checkmark$ & & $\checkmark$ & & \multicolumn{3}{|c|}{ Not Specified } & PSO & & $\begin{array}{l}\text { A multi-objective optimization } \\
\text { algorithm was developed. }\end{array}$ \\
\hline [79] & - $\uparrow$ flow rate & - $v$ & $\checkmark$ & 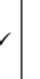 & & $\checkmark$ & $\checkmark$ & & & $\checkmark$ & \multicolumn{3}{|c|}{ Provided by the authority. } & MILP & VISSIM & $\begin{array}{l}\text { Synchro was employed for acquiring } \\
\text { optimize signal timing for the base } \\
\text { scenario. }\end{array}$ \\
\hline
\end{tabular}

\begin{tabular}{|c|c|c|c|c|c|c|c|c|c|c|c|c|c|c|c|c|c|c|}
\hline \multirow{2}{*}{$\begin{array}{l}\text { Reference } \\
\text { Number }\end{array}$} & \multirow{2}{*}{$\begin{array}{c}\text { Context/ } \\
\text { Objective(s) }\end{array}$} & \multirow{2}{*}{ 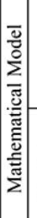 } & \multicolumn{4}{|c|}{ Parameter } & \multicolumn{2}{|c|}{ Intersection } & \multicolumn{2}{|c|}{$\begin{array}{l}\text { Control } \\
\text { System } \\
\text { Strategy }\end{array}$} & \multicolumn{5}{|c|}{ Source of Data } & \multirow{2}{*}{ 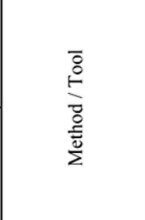 } & \multirow{2}{*}{ 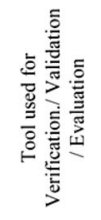 } & \multirow{2}{*}{ Comment } \\
\hline & & & & $\begin{array}{l}\stackrel{0}{E} \\
\stackrel{\Xi}{E} \\
\dot{5}\end{array}$ & 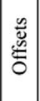 & 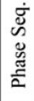 & 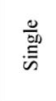 & 产 & 冚 & 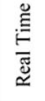 & 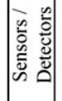 & 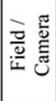 & $\frac{n}{\bar{c}}$ & 永产 & 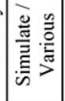 & & & \\
\hline [80] & $\begin{array}{l}- \text { 个 flow rate } \\
\text { through the } \\
\text { intersection }\end{array}$ & 4 & $\checkmark$ & & & $\checkmark$ & & $\checkmark$ & & & & & & & $\checkmark$ & $\begin{array}{l}\text { Rolling } \\
\text { Horizon } \\
\text { Solution } \\
\text { Algorithm }\end{array}$ & & $\begin{array}{l}\text { The proposed solution methodology } \\
\text { divides the network level problem into } \\
\text { an intersection level problem and } \\
\text { solves the MILP model at every } \\
\text { intersection separately. }\end{array}$ \\
\hline [81] & $\begin{array}{c}\text { - optimally tuning } \\
\text { TSC parameter } \\
\end{array}$ & $\bullet$ & & $\checkmark$ & $\checkmark$ & & & $\checkmark$ & $\checkmark$ & & & & & $\checkmark$ & & MILP & $\begin{array}{l}\text { VISSIM, } \\
\text { MATSim }\end{array}$ & \\
\hline [82] & $\begin{array}{l}\text { - obtain network- } \\
\text { level progression } \\
\text { band of TST }\end{array}$ & $\bullet$ & $\checkmark$ & $\checkmark$ & s & & & $\checkmark$ & & $\checkmark$ & $\checkmark$ & & & & & $\begin{array}{l}\text { Decomposition } \\
\text {-Based } \\
\text { Heuristic } \\
\text { Algorithm } \\
\end{array}$ & VISSIM & $\begin{array}{l}\text { Results were compared with some } \\
\text { approaches including Synchro and } \\
\text { MULTIBAND. }\end{array}$ \\
\hline [83] & • optimize TST plan & $\bullet$ & & $\checkmark$ & $\checkmark$ & r & & $\checkmark$ & & $\checkmark$ & & & $\checkmark$ & & $\checkmark$ & $\begin{array}{c}\text { Dynamic } \\
\text { Programming }\end{array}$ & VISSIM & $\begin{array}{l}\text { Results demonstrated that the proposed } \\
\text { model was able to avoid saturation in } \\
\text { the network and minimize the avg. } \\
\text { travel delay }\end{array}$ \\
\hline [84] & $\begin{array}{l}-\uparrow \text { flow rate } \\
\text { through the } \\
\text { network }\end{array}$ & $\bullet$ & $\checkmark$ & $\checkmark$ & $\checkmark$ & & & $\checkmark$ & $\checkmark$ & & & & & & $\checkmark$ & $\begin{array}{c}\text { Benders } \\
\text { Decomposition } \\
\text { \& Benders } \\
\text { Cuts } \\
\text { Technique } \\
\end{array}$ & СTM & \\
\hline [85] & - $\downarrow$ total travel time & 4 & $\checkmark$ & $\checkmark$ & & $\checkmark$ & - & $\checkmark$ & $\checkmark$ & $\checkmark$ & & & $\checkmark$ & $\checkmark$ & & $\mathrm{GA}$ & & $\begin{array}{l}\text { Results showed that the proposed } \\
\text { model worked well if the drivers } \\
\text { considered TST during their route. }\end{array}$ \\
\hline [86] & - optimize TST & $\bullet$ & $\checkmark$ & $\checkmark$ & & $\checkmark$ & $\checkmark$ & & & & & & $\checkmark$ & & & $\begin{array}{c}\text { Convex } \\
\text { (Quadratic) } \\
\text { Prog. } \\
\text { Approach } \\
\end{array}$ & & \\
\hline [87] & $\begin{array}{l}\text { - } \downarrow_{\text {avg. delay at }} \\
\text { intersection }\end{array}$ & $\bullet$ & $\checkmark$ & $\checkmark$ & $\checkmark$ & $\checkmark$ & & $\checkmark$ & & $\checkmark$ & $\checkmark$ & & & & & $\begin{array}{l}\text { Phase } \\
\text { Clearance } \\
\text { Reliability } \\
\text { (PCR) based } \\
\text { approach }\end{array}$ & & $\begin{array}{l}\text { Results from the PCR-based method } \\
\text { was compared with Allsop's \& } \\
\text { Webster's methods and found that the } \\
\text { PCR-based method was able to reduce } \\
\text { the delay in a notable amount. }\end{array}$ \\
\hline
\end{tabular}




\begin{tabular}{|c|c|c|c|c|c|c|c|c|c|c|c|c|c|c|c|c|c|c|}
\hline \multirow{2}{*}{$\begin{array}{l}\text { Reference } \\
\text { Number }\end{array}$} & \multirow{2}{*}{$\begin{array}{c}\text { Context } / \\
\text { Objective(s) }\end{array}$} & \multirow{2}{*}{ 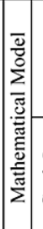 } & \multicolumn{4}{|c|}{ Parameter } & \multicolumn{2}{|c|}{ Intersection } & \multicolumn{2}{|c|}{$\begin{array}{l}\text { Control } \\
\text { System } \\
\text { Strategy }\end{array}$} & \multicolumn{5}{|c|}{ Source of Data } & \multirow{2}{*}{ 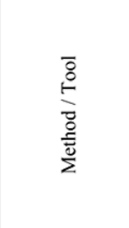 } & \multirow{2}{*}{ 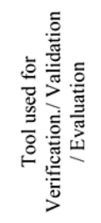 } & \multirow{2}{*}{ Comment } \\
\hline & & & & 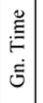 & 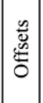 & 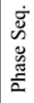 & 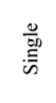 & 产 & 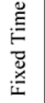 & 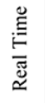 & 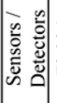 & $\frac{\pi}{2}$ & $\frac{y}{\frac{y}{2}}$ & 空产 & 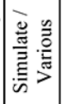 & & & \\
\hline [88] & $\begin{array}{l}-\downarrow \text { average delay } \\
\text { time per person }\end{array}$ & $\bullet$ & $\checkmark$ & $\checkmark$ & & & $\checkmark$ & & & $\checkmark$ & & $\checkmark$ & & & & $\begin{array}{l}\text { Rolling } \\
\text { Horizon }\end{array}$ & VISSIM & \\
\hline [89] & $\begin{array}{l}\text { - optimize phase } \\
\text { timing }\end{array}$ & $\bullet$ & & $\checkmark$ & & $\checkmark$ & $\checkmark$ & & & $\checkmark$ & $\checkmark$ & $\checkmark$ & & & & $\begin{array}{c}\text { Fog } \\
\text { Computing }\end{array}$ & SUMO & \\
\hline [90] & - optimize TST plan & - & $\checkmark$ & $\checkmark$ & & $\checkmark$ & $\checkmark$ & & & $\checkmark$ & & & $\checkmark$ & & & $\begin{array}{l}\text { Person-based } \\
\text { TSC Strategy }\end{array}$ & AIMSUN & $\begin{array}{l}\text { Results revealed that the proposed TSC } \\
\text { strategy reduced total person delay at } \\
\text { the intersection and was effectively } \\
\text { provided the priority to vehicles with } \\
\text { more occupancy. }\end{array}$ \\
\hline [91] & $\begin{array}{l}-\uparrow \text { weighted avg. } \\
\text { flow }\end{array}$ & $\bullet$ & & $\checkmark$ & & $\checkmark$ & & $\checkmark$ & & $\checkmark$ & & & & & $\checkmark$ & $\begin{array}{l}\text { Non-Linear } \\
\text { Optimization } \\
\text { (fmincon) }\end{array}$ & CORSIM & $\begin{array}{l}\text { Bi-level hierarchical control framework } \\
\text { was proposed }\end{array}$ \\
\hline [92] & $\begin{array}{l}-\uparrow \text { flow rate } \\
\text { through the } \\
\text { intersection }\end{array}$ & - & & $\checkmark$ & & $\checkmark$ & $\checkmark$ & & & $\checkmark$ & & & & & $\checkmark$ & $\begin{array}{l}\text { Krill Herd } \\
\text { Algorithm }\end{array}$ & VISSIM & \\
\hline [93] & - optimize TST plan & & $\checkmark$ & $\checkmark$ & $\checkmark$ & & $\checkmark$ & & $\checkmark$ & & & & Speci & & & $\begin{array}{c}\text { Forward- } \\
\text { Simulation } \\
\text { Scheme }+ \\
\text { GA }\end{array}$ & & $\begin{array}{l}\text { This algorithm can easily be used for } \\
\text { calculating the solutions of any TST } \\
\text { setting }\end{array}$ \\
\hline [94] & $\begin{array}{l}-\downarrow \text { total delay at the } \\
\text { intersection }\end{array}$ & & $\checkmark$ & $\checkmark$ & $\checkmark$ & r & . & $\checkmark$ & $\checkmark$ & & & & Speci & & & $\mathrm{SA}+\mathrm{CENEO}$ & & $\begin{array}{l}\text { CENEO (ComplEte NEtwork } \\
\text { Optimisation) }\end{array}$ \\
\hline [95] & $\begin{array}{l}-\downarrow_{\text {avg. delay at }} \\
\text { intersection }\end{array}$ & & $\checkmark$ & $\checkmark$ & & & $\checkmark$ & & $\checkmark$ & & & & $\checkmark$ & & & $\begin{array}{l}\text { Elimination } \\
\text { Pairing } \\
\text { System }\end{array}$ & & $\begin{array}{c}\text { Obtained results were promising when } \\
\text { compared with Webster and Transyt } \\
14 .\end{array}$ \\
\hline
\end{tabular}

\begin{tabular}{|c|c|c|c|c|c|c|c|c|c|c|c|c|c|c|c|c|c|}
\hline \multirow{2}{*}{$\begin{array}{l}\text { Reference } \\
\text { Number }\end{array}$} & \multirow{2}{*}{$\begin{array}{c}\text { Context/ } \\
\text { Objective(s) }\end{array}$} & \multirow{2}{*}{ 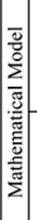 } & \multicolumn{4}{|c|}{ Parameter } & \multicolumn{2}{|c|}{ Intersection } & \multicolumn{2}{|c|}{$\begin{array}{l}\text { Control } \\
\text { System } \\
\text { Strategy }\end{array}$} & \multicolumn{4}{|c|}{ Source of Data } & \multirow{2}{*}{ 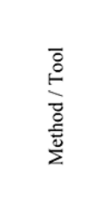 } & \multirow{2}{*}{ 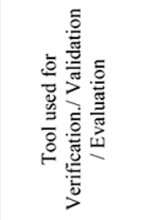 } & \multirow{2}{*}{ Comment } \\
\hline & & & & $\begin{array}{l}\stackrel{0}{\underline{E}} \\
\dot{\vec{\Xi}}\end{array}$ & & 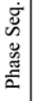 & $\begin{array}{l}\frac{0}{m} \\
\text { 吾 }\end{array}$ & 产 & 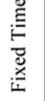 & 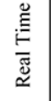 & 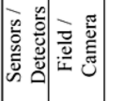 & $\begin{array}{l}n \\
\frac{0}{2} \\
\frac{0}{2} \\
\frac{2}{2}\end{array}$ & 﨎产 & 产产 & & & \\
\hline [96] & - $\downarrow_{\text {avg g total delay }}$ & - & $\checkmark$ & & $\checkmark$ & & $\checkmark$ & & $\checkmark$ & & \multicolumn{4}{|c|}{ Not Specified } & $\begin{array}{c}\text { Nash } \\
\text { Bargaining } \\
\text { Approach }\end{array}$ & INTEGRATION & $\begin{array}{l}\text { An isolated TSC algorithm based on a } \\
\text { game-theoretic optimization } \\
\text { framework. }\end{array}$ \\
\hline [97] & - $\downarrow_{\text {avg }}$. total delay & - & & & & $\checkmark$ & & $\checkmark$ & & $\checkmark$ & $\checkmark$ & & & & $\begin{array}{l}\text { Nash } \\
\text { Bargaining } \\
\text { Approach }\end{array}$ & INTEGRATION & $\begin{array}{l}\text { A decentralized Cycle free TSC } \\
\text { approach was developed. }\end{array}$ \\
\hline [98] & - control TST & & $\checkmark$ & $\checkmark$ & & $\checkmark$ & $\checkmark$ & & $\checkmark$ & & & & & $\checkmark$ & $\begin{array}{c}\text { Rule-based } \\
\text { system+ } \\
\text { Condensed } \\
\text { Nearest } \\
\text { Neighbour } \\
\text { Algorithm. }\end{array}$ & VISSIM & $\begin{array}{l}\text { TSC was developed based on the } \\
\text { biological immune memory and } \\
\text { secondary immune response }\end{array}$ \\
\hline [99] & $\begin{array}{l}- \text { optimize TST } \\
\text { during each cycle }\end{array}$ & $\bullet$ & $\checkmark$ & $\checkmark$ & & & & $\checkmark$ & & $\checkmark$ & & & & $\checkmark$ & $\begin{array}{l}\text { One-Step- } \\
\text { Ahead } \\
\text { Horizon }\end{array}$ & AIMSUN & \\
\hline [100] & $\begin{array}{l}-\downarrow \text { total queue } \\
\text { lengths of all roads } \\
\text { in the network }\end{array}$ & $\bullet$ & $\checkmark$ & $\checkmark$ & $\checkmark$ & & & $\checkmark$ & $\checkmark$ & & & $\checkmark$ & & & $\begin{array}{l}\text { Distributed } \\
\text { Weight } \\
\text { Balancing }\end{array}$ & CORSIM & $\begin{array}{l}\text { The effectiveness of the proposed } \\
\text { control scheme was evaluated by } \\
\text { simulation under different scenarios } \\
\text { and the performance was compared } \\
\text { with the traffic responsive strategy } \\
\text { SCOOT. }\end{array}$ \\
\hline
\end{tabular}

\begin{tabular}{|l}
\hline Legends: \\
$\uparrow:$ Maximize \\
$\downarrow:$ Minimize \\
$\checkmark:$ Deal With \\
$\vdots:$ Available \\
: : Number of \\
Cycl. L: Cycle Length \\
Gn. Time: Green Time \\
\hline
\end{tabular}

\begin{tabular}{|c|c|}
\hline $\begin{array}{l}\text { Phase Seq.: Phase Sequence } \\
\text { GA: Genetic Algorithm } \\
\text { HS: Harmony Search } \\
\text { RL: Reinforcement Learning } \\
\text { ANFIS: Adaptive Neuro-Fuzzy Inference System } \\
\text { NN: Neural Network } \\
\text { NSGA-II: Non-dominated Sorting GA }\end{array}$ & $\begin{array}{l}\text { EA: Evolutionary Algorithm } \\
\text { SA Simulated Anncaling } \\
\text { CTM: Cell Transmission Model } \\
\text { CORIM: CRRridor SMMulation } \\
\text { Transy-tFF: TRAffic Network StudY Tool. } \\
\text { version 7F } \\
\text { LS: Local Scarch Algorithm } \\
\text { BC. Bec Colonv Allorithm }\end{array}$ \\
\hline
\end{tabular}

PSO: Particle Swarm Optimization

DGA: Decentralize $G$

ABC: Artificial BC
TS: Tabu Search

MINLP: Mixed Integer Non-Linear Program SPSA: Simultancous Perturbation Stochastic Approximation 


\section{Abbreviations}

ABC: Artificial Bee Colony Algorithm; ACO: Ant Colony Optimization; AIMSUN: Advanced Interactive Microscopic Simulator for Urban and nonurban Networks; ANFIS: Adaptive Neuro-Fuzzy Inference System; BC: Bee Colony algorithm; Cl: Computational Intelligence; CS: Cuckoo Search; CTM: Cell Transmission Model; CORSIM: CORridor SIMulation; Cycl. L: Cycle Length; DE: Differential Evolution; DGA: Decentralized GA; EA: Evolutionary Algorithm; EC : Evolutionary Computation; GA: Genetic Algorithm; GP: Genetic Programming; GUl: Graphical User Interface; HS: Harmony Search; IT2ANFIS: Interval Type-2 Adaptive Neuro-Fuzzy Inference System; ITS: Intelligent Transportation System; LS: Local Search algorithm; MA: Memetic Algorithm; MATSim : Multi-Agent Transport SIMulation; MILP: Mixed Integer Linear Programming; MODEA: Multi-Objective Differential Evolutionary Algorithm; MINLP: Mixed Integer Non Linear Programming; NN: Neural Network; NSGA: Non-dominated Sorting Genetic Algorithm; Paramics: PARAllel MICroscopic Simulation; Phase Seq.: Phase Sequence; PSO: Particle Swarm Optimization; RL: Reinforcement Learning; SA: Simulated Annealing; SI: Swarm Intelligence; SPSA: Simultaneous Perturbation Stochastic Approximation; SUMO : Simulation of Urban Mobility; SimOpt: SIMulation-based OPTimization; TS: Tabu Search; TSC : Traffic Signal Control; TST: Traffic Signal Timing; Transyt-7F: TRAffic Network StudY Tool, version 7F; UTOPIA: Urban Traffic Optimization by Integrated Automation; VISSIM: Verkehr In Städten -SIMulationsmodell

\section{Acknowledgements}

Not Applicable.

\section{Authors' contributions}

The authors declare that they all contributed to the research for this article, drafting the manuscript and that they approved submission.

\section{Funding}

Not Applicable.

\section{Availability of data and materials}

Not Applicable.

\section{Competing interests}

The authors declare that they have no competing interests.

Received: 7 February 2020 Accepted: 12 August 2020 Published online: 09 October 2020

\section{References}

1. Litman, T. A. (2003). Transportation cost and benefit analysis: Techniques, estimates and implications. Victoria: Victoria Transport Policy Institute.

2. Fyhri, A., \& Marit, G. (2010). Science of the Total environment noise, sleep and poor health : Modeling the relationship between road traf fi c noise and cardiovascular problems. Science of the Total Environment, 408, 49354942. https://doi.org/10.1016/j.scitotenv.2010.06.057.

3. Agarwal, S., \& Swami, B. L. (2011). Road traffic noise, annoyance and community health survey - a case study for an Indian city. Noice Heal, 13, 272-277. https://doi.org/10.4103/1463-1741.82959.

4. Howell, W. C., \& Fu, M. C. (2006). Simulation optimization of traffic light signal timings via perturbation analysis doctoral dissertation, University of Maryland.

5. Zhao, D., Dai, Y., \& Zhang, Z. (2012). Computational intelligence in urban traffic signal control: A survey. IEEE Transactions on Systems, Man, and Cybernetics Part C: Applications and Reviews, 42, 485-494. https://doi.org/10. 1109/TSMCC.2011.2161577.

6. Tan, M. K., Chuo, H. S. E., Chin, R. K. Y., et al. (2017). Genetic algorithm based signal optimizer for oversaturated urban signalized intersection. In 2016 IEEE Int Conf Consum electron ICCE-Asia 2016 5-8. https://doi.org/10.1109//CCEAsia.2016.7804762

7. Sabar, N. R., Kieu, L. M., Chung, E., et al. (2017). A memetic algorithm for real world multi-intersection traffic signal optimisation problems. Engineering Applications of Artificial Intelligence, 63, 45-53. https://doi.org/10.1016/j. engappai.2017.04.021.

8. Akcelik, R. (1981). Traffic signals: Capacity and timing analysis, (vol. 123). Melbourne: Australian Road Research Board, ARR.
9. Koukol, M., I, L. Z., Marek, L., \& I, P. T. (2015). Fuzzy logic in traffic engineering : A review on signal control. Mathematical Problems in Engineering, 2015, 1-14. https://doi.org/10.1155/2015/979160.

10. Araghi, S., Khosravi, A., \& Creighton, D. (2015). A review on computational intelligence methods for controlling traffic signal timing. Expert Systems with Applications, 42, 1538-1550. https://doi.org/10.1016/j.eswa.2014.09.003.

11. Yu, Q., Liu, J. G., Liu, P. H., et al. (2009). Dynamic optimization project study between the traffic organization and the traffic signal control of urban traffic. 2009 WRI World Congress Computer Science Information Engineering CSIE 2009, 3, 182-186. https://doi.org/10.1109/CSIE.2009.63.

12. Ng, K. M., Reaz, M. B. I., Ali, M. A. M., \& Chang, T. G. (2013). A brief survey on advances of control and intelligent systems methods for traffic-responsive control of urban networks. Teh Vjesn, 3, 555-562.

13. Papageorgiou, M., Diakaki, C., Dinopoulou, V., et al. (2003). Review of road traffic control strategies. Proceedings of the IEEE, 91, 2043-2067.

14. Ribeiro, I. M., \& Simöes, M. D. L. D. O. (2016). The fully actuated traffic contro problem solved by global optimization and complementarity. Engineering Optimization, 48, 199-212. https://doi.org/10.1080/0305215X.2014.995644.

15. Webster, F. V. (1958). Traffic signal setting. Road Research Laboratory Technical Paper /UK, 39, 1-44.

16. Miller, A. J. (1963). Settings for fixed-cycle traffic signals. The Journal of the Operational Research Society, 14, 373-386. https://doi.org/10.2307/ 3006800 .

17. Küçükoğlu, I., Dewil, R., \& Cattrysse, D. (2019). Hybrid simulated annealing and tabu search method for the electric travelling salesman problem with time windows and mixed charging rates. Expert Systems with Applications, 134, 279-303. https://doi.org/10.1016/j.eswa.2019.05.037.

18. Ratrout, N. T., \& Rahman, S. M. (2009). A comparative analysis of currently used microscopic and macroscopic traffic simulation software. Arabian Journal for Science and Engineering, 34, 121-133.

19. Salgado, D., Jolovic, D., Martin, P. T., \& Aldrete, R. M. (2016). Traffic microsimulation models assessment-a case study of international land port of entry. Procedia - Procedia Computer Science, 83, 441-448. https://doi.org/ 10.1016/.jprocs.2016.04.207.

20. Deng, G. (2007). Simulation-based optimization doctoral dissertation, University of Wisconsin-Madison.

21. Carson, Y., \& Maria, A. (1997). Simulation optimization: Methods and applications. In S. Andradóttir, K. J. Healy, D. H. Winters, \& B. L. Nelson (Eds.) Proceedings of the 1997 winter simulation conference, (pp. 118-126).

22. Araghi, S., Khosravi, A., \& Creighton, D. (2015). Intelligent cuckoo search optimized traffic signal controllers for multi-intersection network. Expert Systems with Applications, 42, 4422-4431. https://doi.org/10.1016/j.eswa.2015. 01.063 .

23. Jin, J., Ma, X., \& Kosonen, I. (2017). An intelligent control system for traffic lights with simulation-based evaluation. Control Engineering Practice, 58, 2433. https://doi.org/10.1016/..conengprac.2016.09.009.

24. Araghi, S., Khosravi, A., Creighton, D., \& Nahavandi, S. (2017). Influence of meta-heuristic optimization on the performance of adaptive interval type2fuzzy traffic signal controllers. Expert Systems with Applications, 71, 493-503. https://doi.org/10.1016/j.eswa.2016.10.066

25. Miletić, M., Kapusta, B., \& Ivanjko, E. (2018). Comparison of two approaches for preemptive traffic light control. In Proc Elmar - Int Symp electron, (pp. 57-62). https://doi.org/10.23919/ELMAR.2018.8534608.

26. Vogel, A., Oremovi, I., Simi, R., \& Ivanjko, E. (2018). Improving traffic light control by means of fuzzy logic. In In 2018 international symposium ELMAR, (pp. 16-19).

27. Wei, H., Zheng, G., Yao, H., \& Li, Z. (2018). Intellilight: A reinforcement learning approach for intelligent traffic light control. In In proceedings of the 24th ACM SIGKDD international conference on Knowledge Discovery \& Data Mining, (pp. 2496-2505).

28. Garg, D., Chli, M., \& Vogiatzis, G. (2018). Deep reinforcement learning for autonomous traffic light control. In 2018 3rd IEEE international conference on intelligent transportation engineering, ICITE 2018, (pp. 214-218). https://doi. org/10.1109//CITE.2018.8492537.

29. Gökçe, M. A., Öner, E., \& Işık, G. (2015). Traffic signal optimization with particle swarm optimization for signalized roundabouts. Simulation, 91, 456466. https://doi.org/10.1177/0037549715581473.

30. Dabiri, S., \& Abbas, M. (2016). Arterial traffic signal optimization using particle swarm optimization in an integrated VISSIM-MATLAB simulation environment. In IEEE Conf Intell Transp Syst proceedings, ITSC, (pp. 766-771). https://doi.org/10.1109/TSC.2016.7795641. 
31. Panovski, D., \& Zaharia, T. (2016). Simulation-based vehicular traffic lights optimization. In In 2016 12th international conference on signal-image Technology \& Internet-Based Systems, (pp. 258-265). https://doi.org/10.1109/ SITIS.2016.49.

32. Elgarej, M., Khalifa, M., \& Youssfi, M. (2016). Traffic lights optimization with distributed ant colony optimization based on multi-agent system. International Conference Networked System, 266-279. https://doi.org/10.1007/ 978-3-642-60749-3_9.

33. Jintamuttha, K., Watanapa, B., \& Charoenkitkarn, N. (2016). Dynamic traffic light timing optimization model using bat algorithm. In In 2016 2nd international conference on control science and systems engineering (ICCSSE), (pp. 181-185). https://doi.org/10.1109/CCSSE.2016.7784378.

34. Ahmed, E. K. E., Khalifa, A. M. A., \& Kheiri, A. (2018). Evolutionary computation for static traffic light cycle optimisation. International Conference on Computer Control Electric Electron Engineering, 2018, 1-6.

35. Chuo, H. S. E., Tan, M. K., Chong, A. C. H., et al. (2017). Evolvable traffic signal control for intersection congestion alleviation with enhanced particle swarm optimisation. Proc - 2017 IEEE. In 2nd Int Conf autom control Intell Syst I2CACIS 2017 2017-Decem, (pp. 92-97). https://doi.org/10.1109/I2CACIS. 2017.8239039

36. Nguyen, P. T. M., Passow, B. N., \& Yang, Y. (2016). Improving anytime behavior for traffic signal control optimization based on NSGA-II and local search. Proceedings of International Joint Conference on Neural Networks, 4611-4618. https://doi.org/10.1109/IJCNN.2016.7727804.

37. Hatri, C. E. L., \& Boumhidi, J. (2016). Q-learning based intelligent multiobjective particle swarm optimization of light control for traffic urban congestion management. In In 2016 4th IEEE international colloquium on information science and technology (CiSt), (pp. 794-799). https://doi.org/10. 1109/CIST.2016.7804996.

38. Zheng, L., Xu, C., Jin, P. J., \& Ran, B. (2019). Network-wide signal timing stochastic simulation optimization with environmental concerns. Applied Soft Computing - Journal, 77, 678-687. https://doi.org/10.1016/j.asoc.2019.01.046.

39. Hajbabaie, A., \& Benekohal, R. F. (2015). A program for simultaneous network signal timing optimization and traffic assignment. IEEE Transactions on Intelligent Transportation Systems, 16, 2573-2586. https://doi.org/10.1109/ TITS.2015.2413360

40. Li, Z., Shahidehpour, M., Bahramirad, S., \& Khodaei, A. (2017). Optimizing traffic signal settings in smart cities. IEEE Transactions on Smart Grid, 8 , 2382-2393. https://doi.org/10.1109/TSG.2016.2526032.

41. Chen, S., \& Sun, D. J. (2016). An improved adaptive signal control method for isolated signalized intersection based on dynamic programming. IEEE Intelligent Transportation Systems Magazine, 8, 4-14

42. Ahmed, F., \& Hawas, Y. E. (2015). An integrated real-time traffic signal system for transit signal priority, incident detection and congestion management. Transport Research Part C Emerging Technology, 60, 52-76. https://doi.org/10.1016/j.trc.2015.08.004.

43. Dakic, I., Raton, B., \& Raton, B. (2015). Backpressure traffic control algorithms in field-like signal operations. In In 2015 IEEE 18th international conference on intelligent transportation systems, (pp. 137-142). https://doi.org/10.1109/ITSC. 2015.31.

44. Pavleski, D., Koltovska-Nechoska, D., \& Ivanjko, E. (2017). Evaluation of adaptive traffic control system UTOPIA using microscopic simulation. Proc Elmar - International Symposium of Electron, 17-20. https://doi.org/10.23919/ ELMAR.2017.8124425.

45. Chen, X., Osorio, C., \& Santos, B. F. (2017). Simulation-based travel time reliable signal control. Transportation Science, 1-22. https://doi.org/10.1287/ trsc.2017.0812.

46. Baldi, S., Michailidis, I., Ntampasi, V., et al. (2019). A simulation-based traffic signal control for congested urban traffic networks. Transportation Science, 53, 6-20. https://doi.org/10.1287/trsc.2017.0754.

47. Shah, S., Mohiuddin, S., Gokce, M. A., et al. (2019). Analysis of various scenarios to mitigate congestion at a signalized roundabout using microsimulation. In 2019 innovations in intelligent systems and applications conference (ASYU), (pp. 1-6). https://doi.org/10.1109/ASYU48272.2019.8946339.

48. Zheng, L., Xue, X., Xu, C., \& Ran, B. (2019). A stochastic simulation-based optimization method for equitable and efficient network-wide signal timing under uncertainties. Transport Research Part B Methodology, 122, 287-308. https://doi.org/10.1016/j.trb.2019.03.001.

49. Venayagamoorthy, G. K. (2009). A successful interdisciplinary course on computational intelligence. EEE Computer Intelligence Magnet, 4, 14-23. https://doi.org/10.1109/MCl.2008.930983.
50. Parpinelli, R. S., \& Lopes, H. S. (2011). New inspirations in swarm intelligence: A survey. International Journal of Bio-Inspired Computer, 3, 1. https://doi.org/ 10.1504/IJBIC.2011.038700.

51. Eiben, A. E., \& Smith, J. E. (2012). Introduction to evolutionary computing genetic algorithms, (2nd ed., ). Berlin: Springer Netherlands.

52. Montana, D. J., \& Czerwinski, S. (1996). Evolving control laws for a network of traffic signals. In Proceedings of the 1st annual conference on genetic programming, (pp 333-338). ISBN:0-262- 61127-9.

53. Montana, D. J. (1995). Strongly typed genetic programming. Evolutionary Computation, 3, 199-230.

54. Xiang, J., \& Chen, Z. (2015). Adaptive traffic signal control of bottleneck subzone based on grey qualitative reinforcement learning algorithm. In international conference on pattern recognition applications and methods (ICPRAM), (pp. 295-301). https://doi.org/10.5220/0005269302950301.

55. Benhamza, K., \& Seridi, H. (2015). Adaptive traffic signal control in multiple intersections network. Journal of Intelligent Fuzzy Systems, 28, 2557-2567. https://doi.org/10.3233/IFS-151535.

56. Vidhate, D. A., \& Kulkarni, P. (2017). Cooperative multi-agent reinforcement learning models (CMRLM) for intelligent traffic control. In Proc - 1st Int Conf Intell Syst Inf Manag ICISIM 2017 2017-Janua, (pp. 325-331). https://doi.org/ 10.1109/ICISIM.2017.8122193.

57. Genders, W., \& Razavi, S. (2018). Evaluating reinforcement learning state representations for adaptive traffic signal control. Procedia Computer Science, 130, 26-33. https://doi.org/10.1016/j.procs.2018.04.008.

58. Liang, X., Du, X., Member, S., \& Wang, G. (2019). A deep reinforcement learning network for traffic light cycle control. IEEE Transactions on Vehicular Technology, 68, 1243-1253. https://doi.org/10.1109/TVT.2018. 2890726.

59. Bernas, M., \& Płaczek, B. (2019). A neuroevolutionary approach to controlling traffic signals based on data from sensor network. Sensors, 19, 1-24. https://doi.org/10.3390/s19081776.

60. Abdelgawad, H., Abdulhai, B., El-tantawy, S., et al. (2015). Assessment of selflearning adaptive traffic signal control on congested urban areas : Independent versus coordinated perspectives. Canadian Journal of Civil Engineering, 42, 353-366. https://doi.org/10.1139/cjce-2014-0503.

61. Ozan, C., Baskan, O., Haldenbilen, S., \& Ceylan, H. (2015). A modified reinforcement learning algorithm for solving coordinated signalized networks. Transport Research Part C Emerging Technology, 54, 40-55. https://doi.org/10.1016/j.trc.2015.03.010.

62. Li, Z., \& Schonfeld, P. (2015). Hybrid simulated annealing and genetic algorithm for optimizing arterial signal timings under oversaturated traffic conditions. Journal of Advanced Transportation, 49, 153-170. https://doi.org/ 10.1002/atr.1274.

63. Gao, K., Zhang, Y., Sadollah, A., \& Su, R. (2016). Optimizing urban traffic light scheduling problem using harmony search with ensemble of local search. Applied Soft Computing - Journal, 48, 359-372. https://doi.org/10.1016/j.asoc. 2016.07.029.

64. Bie, Y., Cheng, S., \& Liu, Z. (2017). Optimization of signal-timing parameters for the intersection with hook turns. Transport, 32, 233-241. https://doi.org/ 10.3846/16484142.2017.1285813.

65. Tan, M. K., Chuo, H. S. E., Chin, R. K. Y., et al. (2017). Optimization of traffic network signal timing using decentralized genetic algorithm. In 2017 IEEE 2nd international conference on automatic control and intelligent systems, 12CACIS 2017, (pp. 62-67).

66. Jovanović, A., \& Teodorović, D. (2017). Pre-timed control for an undersaturated and over-saturated isolated intersection: A bee Colony optimization approach. Transportation Planning and Technology, 40, 556-576. https://doi.org/10.1080/03081060.2017.1314498.

67. Tarek, Z., Al-rahmawy, M., \& Tolba, A. (2018). Fog computing for optimized traffic control strategy. Journal of Intelligent Fuzzy Systems. https://doi.org/10. 3233/JIFS-18077.

68. Manandhar, B., \& Joshi, B. (2018). Adaptive traffic light control with statistical multiplexing technique and particle swarm optimization in smart cities. Proceedings on 2018 IEEE 3rd International Conference Comput Communication Security ICCCS, 2018, 210-217. https://doi.org/10.1109/CCCS. 2018.8586845

69. Eduardo, P., De Almeida, M., Chung, E., et al. (2017). Active control for traffic lights in regions and corridors: An approach based on evolutionary computation based on evolutionary computation. Transport Research Procedia, 25, 1769-1780. https://doi.org/10.1016/j. trpro.2017.05.140 
70. Gao, Y., Liu, Y., Hu, H., \& Ge, Y. E. (2018). Signal optimization for an isolated intersection with illegal permissive left-turning movement. Transportation B Transport Dynamic, 0566. https://doi.org/10.1080/ 21680566.2018.1518734.

71. Guo, J., Kong, Y., Li, Z., et al. (2019). A model and genetic algorithm for areawide intersection signal optimization under user equilibrium traffic. Mathematics and Computers in Simulation, 155, 92-104. https://doi.org/10. 1016/j.matcom.2017.12.003

72. Gao, K., Zhang, Y., Su, R., et al. (2019). Solving traffic signal scheduling problems in heterogeneous traffic network by using meta-heuristics. IEEE Transactions on Intelligent Transportation Systems, 20, 3272-3282. https://doi.org/10.1109/TITS.2018.2873790.

73. Jiao, P., Li, R., \& Li, Z. (2016). Pareto front-based multi-objective real-time traffic signal control model for intersections using particle swarm optimization algorithm. Advances in Mechanical Engineering, 8, 1-15. https://doi.org/10.1177/1687814016666042.

74. Zhang, Y., \& Zhou, Y. (2018). Distributed coordination control of traffic network flow using adaptive genetic algorithm based on cloud computing. Journal of Network and Computer Applications, 119, 110-120. https://doi.org/ 10.1016/j.jnca.2018.07.001.

75. Hao, W., Ma, C., Moghimi, B., et al. (2018). Robust optimization of signal control parameters for unsaturated intersection based on tabu searchartificial bee colony algorithm. IEEE Access, 6, 32015-32022. https://doi.org/ 10.1109/ACCESS.2018.2845673.

76. Yu, D., Tian, X., Xing, X., \& Gao, S. (2016). Signal timing optimization based on fuzzy compromise programming for isolated signalized intersection. Mathematical Problems in Engineering, 2016, 1-12. https://doi.org/10.1155/2016/1682394.

77. Zhao, H., Han, G., \& Niu, X. (2019). The signal control optimization of road intersections with slow traffic based on improved PSO. Mobile Networks and Applications. https://doi.org/10.1007/s11036-019-01225-7.

78. Jia, H., Lin, Y., Luo, Q., et al. (2019). Multi-objective optimization of urban road intersection signal timing based on particle swarm optimization algorithm. Advances in Mechanical Engineering, 11, 1-9. https://doi.org/10. 1177/1687814019842498.

79. He, Q., Kamineni, R., \& Zhang, Z. (2016). Traffic signal control with partial grade separation for oversaturated conditions. Transport Research Part C Emerging Technology, 71, 267-283. https://doi.org/10.1016/j.trc.2016.08.001.

80. Mehrabipour, M., \& Hajbabaie, A. (2017). A cell-based distributedcoordinated approach for network-level signal timing optimization. Computer-Aided Civil and Infrastructure Engineerin, 32, 599-616. https://doi. org/10.1111/mice.12272.

81. Köhler, E., \& Strehler, M. (2018). Traffic signal optimization : Combining static and dynamic models. Transportation Science, 1-21. https://doi.org/10.1287/ trsc.2017.0760

82. Yan, H., He, F., Lin, X., et al. (2019). Network-level multiband signal coordination scheme based on vehicle trajectory data. Transport Research Part C Emerging Technology, 107, 266-286. https://doi.org/10.1016/j.trc.2019.08.014.

83. Xu, M., An, K., Vu, L. H., et al. (2019). Optimizing multi-agent based urban traffic signal control system. Journal of Intelligent Transportation Systems, 23, 357-369. https://doi.org/10.1080/15472450.2018.1501273.

84. Mohebifard, R., \& Hajbabaie, A. (2019). Optimal network-level traffic signal control : A benders decomposition-based solution algorithm. Transport Research Part $B$ Methodology, 121, 252-274. https://doi.org/10.1016/j.trb.2019.01.012.

85. Yu, H., Ma, R., \& Zhang, H. M. (2018). Optimal traffic signal control under dynamic user equilibrium and link constraints in a general network. Transport Research Part B Methodology, 110, 302-325. https://doi.org/10. 1016/j.trb.2018.02.009.

86. Yu, C., Ma, W., Han, K., \& Yang, X. (2017). Optimization of vehicle and pedestrian signals at isolated intersections. Transport Research Part $B$ Methodology, 98, 135-153. https://doi.org/10.1016/j.trb.2016.12.015.

87. Ma, W., An, K., \& Lo, H. K. (2016). Multi-stage stochastic program to optimize signal timings under coordinated adaptive control. Transport Research Part C Emerging Technology, 72, 342-359. https://doi.org/10. 1016/j.trc.2016.10.002.

88. Jiao, P., Li, Z., Liu, M., et al. (2015). Real-time traffic signal optimization model based on average delay time per person. Advances in Mechanical Engineering, 7, 1-11. https://doi.org/10.1177/1687814015613500.

89. Simoni, M. D., \& Claudel, C. G. (2017). A semi-analytic approach to model signal plans in urban corridors and its application in metaheuristic optimization. Transportation B Transport Dynamic, 0566, 1-18. https://doi. org/10.1080/21680566.2017.1370397.
90. Memoli, S., Cantarella, G. E., de Luca, S., \& Di Pace, R. (2017). Network signal setting design with stage sequence optimisation. Transport Research Part B Methodology, 100, 20-42. https://doi.org/10.1016/j.trb. 2017.01.013.

91. Eriskin, E., Karahancer, S., Terzi, S., \& Saltan, M. (2017). Optimization of traffic signal timing at oversaturated intersections using elimination pairing system. Procedia Engineering, 187, 295-300. https://doi.org/10.1016/j.proeng. 2017.04.378.

92. Abdelghaffar, H. M., Yang, H., \& Rakha, H. A. (2016). Isolated traffic signal control using Nash bargaining optimization. Global Journal of Research Engineering B Automotion Engineering, 16, 26-36. https://doi.org/10.1109/ ITSC.2016.7795755.

93. Abdelghaffar, H. M., Yang, H., \& Rakha, H. A. (2017). Developing a decentralized cycle-free Nash bargaining arterial traffic signal controller. 5th IEEE International Conference Model Technology Intelligence Transport System MT-ITS 2017 - Proc, 544-549. https://doi.org/10.1109/MTITS.2017. 8005732.

94. Louati, A., Elkosantini, S., Darmoul, S., \& Ben Said, L. (2019). An immune memory inspired case-based reasoning system to control interrupted flow at a signalized intersection. Artificial Intelligence Review, 52, 2099-2129. https://doi.org/10.1007/s10462-017-9604-0.

95. Grandinetti, P., Canudas-De-Wit, C., \& Garin, F. (2019). Distributed optimal traffic lights design for large-scale urban networks. IEEE Transactions on Control Systems Technology, 27, 950-963. https://doi.org/10.1109/TCST.2018. 2807792.

96. Wu, N., Li, D., \& Xi, Y. (2019). Distributed weighted balanced control of traffic signals for urban traffic congestion. IEEE Transactions on Intelligent Transportation Systems, 20, 3710-3720. https://doi.org/10.1109/TITS.2018. 2878001.

97. Tang, C., Xia, S., Zhu, C., \& Wei, X. (2019). Phase timing optimization for smart traffic control based on fog computing. IEEE Access, 7, 84217-84228. https://doi.org/10.1109/ACCESS.2019.2925134.

98. Vilarinho, C., Tavares, J. P., \& Rossetti, R. J. F. (2017). Intelligent traffic lights: Green time period negotiaton. Transport Research Procedia, 22, 325-334. https://doi.org/10.1016/j.trpro.2017.03.039.

99. Zhou, Z., De Schutter, B., Lin, S., \& Xi, Y. (2017). Two-level hierarchical modelbased predictive control for large-scale urban traffic networks. IEEE Transactions on Control Systems Technology, 25, 496-508. https://doi.org/10. 1109/TCST.2016.2572169.

100. Zhihui, L. I., Qian, C. A. O., Yonghua, Z., et al. (2019). Krill herd algorithm for signal optimization of cooperative control with traffic supply and demand. IEEE Access, 7, 10776-10786. https://doi.org/10. 1109/ACCESS.2019.2891791.

101. Tong, Y., Zhao, L., Li, L., \& Zhang, Y. (2015). Stochastic programming model for oversaturated intersection signal timing. Transport Research Part C Emerging Technology, 58, 474-486. https://doi.org/10.1016/j.trc. 2015.01.019.

102. Castillo, R. G., Clempner, J. B., \& Poznyak, A. S. (2015). Solving the multi-traffic signal-control problem for a class of continuous-time markov games. In 2015 12th international conference on electrical engineering, computing science and automatic control (CCE), (pp. 1-5). https://doi.org/10.1109/ICEEE. 2015.7357932.

103. Chen, Y., Chen, K., \& Hsiung, P. (2016). Dynamic traffic light optimization and control system using model-predictive control method, (pp. 2366-2371). Rio de Janeiro: 2016 IEEE 19th international conference on intelligent transportation systems (ITSC).

104. Zhao, C., Chang, Y., \& Zhang, P. (2018). Coordinated control model of mainsignal and pre-signal for intersections with dynamic waiting lanes. Sustainability, 10, 1-14. https://doi.org/10.3390/su10082849.

105. Van De Weg, G. S., Vu, H. L., Hegyi, A., \& Hoogendoorn, S. P. (2019). A hierarchical control framework for coordination of intersection signal timings in all traffic regimes. IEEE Transactions on Intelligent Transportation Systems, 20, 1815-1827. https://doi.org/10.1109/TITS.2018.2837162.

106. Mohajerpoor, R., Saberi, M., \& Ramezani, M. (2019). Analytical derivation of the optimal traffic signal timing: Minimizing delay variability and spillback probability for undersaturated intersections. Transport Research Part B Methodology, 119, 45-68. https://doi.org/10. 1016/j.trb.2018.11.004.

107. Azhar, A. M., \& Svante, B. (2011). Signal control of roundabouts. Procedia Social and Behavioral Sciences, 16, 729-738. https://doi.org/10.1016/j.sbspro. 2011.04.492 
108. Akçelik, R. (2011). Roundabout metering signals: Capacity, performance and timing. Procedia - Social and Behavioral Sciences, 16, 686-696. https://doi. org/10.1016/j.sbspro.2011.04.488.

109. Inman, V. W., \& Davis, G. W. (2007). Synthesis of literature relevant to roundabout signalization to provide pedestrian access Access-Board.

110. Robinson, B. W., Rodegerdts, L., Scarborough, W., et al. (2000). Roundabouts: An informational guide United States Fed Highw Adm, (p. 400).

111. Digital twin. https:/en.wikipedia.org/wiki/Digital_twin. Accessed 20 May 2020

\section{Publisher's Note}

Springer Nature remains neutral with regard to jurisdictional claims in published maps and institutional affiliations.

\section{Submit your manuscript to a SpringerOpen ${ }^{\circ}$ journal and benefit from:}

- Convenient online submission

- Rigorous peer review

- Open access: articles freely available online

High visibility within the field

- Retaining the copyright to your article

Submit your next manuscript at $\boldsymbol{\wedge}$ springeropen.com 